\title{
Analysis of Gene Expression in Human Dermal Fibroblasts Treated with Senescence-Modulating COX Inhibitors
}

\author{
Jeong A. Han ${ }^{1 *}$, Jong-Il Kim²,3,4* \\ ${ }^{1}$ Department of Biochemistry and Molecular Biology, Kangwon National University School of Medicine, Chuncheon 24341, Korea, \\ ${ }^{2}$ Department of Biochemistry and Molecular Biology, Seoul National University College of Medicine, Seoul 03080, Korea, \\ ${ }^{3}$ Cancer Research Institute, Seoul National University College of Medicine, Seoul 03080, Korea, \\ ${ }^{4}$ Department of Biomedical Sciences, Seoul National University Graduate School, Seoul 03080, Korea
}

\begin{abstract}
We have previously reported that NS-398, a cyclooxygenase-2 (COX-2)-selective inhibitor, inhibited replicative cellular senescence in human dermal fibroblasts and skin aging in hairless mice. In contrast, celecoxib, another COX-2-selective inhibitor, and aspirin, a non-selective COX inhibitor, accelerated the senescence and aging. To figure out causal factors for the senescence-modulating effect of the inhibitors, we here performed cDNA microarray experiment and subsequent Gene Set Enrichment Analysis. The data showed that several senescence-related gene sets were regulated by the inhibitor treatment. NS-398 up-regulated gene sets involved in the tumor necrosis factor $\beta$ receptor pathway and the fructose and mannose metabolism, whereas it down-regulated a gene set involved in protein secretion. Celecoxib up-regulated gene sets involved in G2M checkpoint and E2F targets. Aspirin up-regulated the gene set involved in protein secretion, and down-regulated gene sets involved in RNA transcription. These results suggest that COX inhibitors modulate cellular senescence by different mechanisms and will provide useful information to understand senescence-modulating mechanisms of COX inhibitors.
\end{abstract}

Keywords: cyclooxygenase 2, fibroblast, gene set enrichment analysis, inhibitor, senescence

\section{Introduction}

Prostaglandin endoperoxide synthase, also called as cyclooxygenase (COX), is an enzyme converting arachidonic acid to prostaglandin $\mathrm{H}_{2}\left(\mathrm{PGH}_{2}\right)$. $\mathrm{PGH}_{2}$ is a common precursor for prostanoid biosynthesis such as $\mathrm{PGD}_{2}, \mathrm{PGE}_{2}$, $\mathrm{PGF}_{2} \alpha, \mathrm{PGI}_{2}$, and thromboxane $\mathrm{A}_{2}$. These prostanoids are known to be important chemical mediators for inflammation as well as other biological processes [1]. There are two isoforms of COX. COX-1 (PTGS1) is expressed constitutively in most cells and responsible for basal level of prostanoid biosynthesis. COX-2 (PTGS2) is induced by various stimuli such as bacterial endotoxins, cytokines, genotoxic agents, growth factors, or oncogene products $[2,3]$.

Most non-steroidal anti-inflammatory drugs are COX inhibitors. These drugs inhibit the COX catalytic activity by occupying the active site of COX. Aspirin, ibuprofen, or flurbiprofen is a non-selective COX inhibitor, which inhibits both COX-1 and COX-2 catalytic activity. In contrast, NS-398, celecoxib, or nimesulide is a selective COX-2 inhibitor, which inhibits COX-2 catalytic activity specifically $[3,4]$.

The mechanism of aging has not been fully understood. However, it has been proposed that the pro-inflammatory catalytic activity of COX-2 is a causal factor for aging. The hypothesis proposes that reactive oxygen species (ROS) generated in the process of normal metabolism or inflammation activate the transcription factor nuclear factor $\kappa \mathrm{B}$ $(\mathrm{NF}-\kappa \mathrm{B})$. NF- $\kappa \mathrm{B}$ increases the transcription of proinflammatory target genes such as COX-2, which in turn stabilizes a chronic inflammatory circuit by generating ROS. This chronic inflammation causes tissue damage and aging [5].

If the pro-inflammatory catalytic activity of COX-2 is a causal factor for aging, COX-2 inhibitors should conceivably 
inhibit aging. In this context, we have previously examined the effect of COX-2 inhibitors on aging both in the replicative cellular senescence model of human dermal fibroblasts (HDFs) and in the intrinsic skin aging model of hairless mice. We observed that among three selective COX-2 inhibitors studied, only NS-398 inhibited the cellular senescence whereas celecoxib and nimesulide accelerated the senescence. In addition, three non-selective COX inhibitors including aspirin, ibuprofen, and flurbiprofen accelerated the senescence [6]. Also, we observed that only NS-398 inhibited the skin aging while celecoxib and aspirin accelerated the skin aging in hairless mice [3]. These studies strongly suggest that the pro-inflammatory catalytic activity of COX-2 is not a causal factor for aging and that the aging-modulating effect of COX inhibitors is attributable to a catalytic activity-independent mechanism.

In an attempt to figure out underlying mechanisms by which COX inhibitors modulate aging, we here performed cDNA microarray experiment and subsequent Gene Set Enrichment Analysis (GSEA) in HDFs treated with three COX inhibitors, NS-398, celecoxib, and aspirin.

\section{Methods}

\section{Materials and cell culture}

NS-398 and aspirin were purchased from Cayman Chemicals (Ann Arbor, MI, USA). Celecoxib was a generous gift from Dr. S.V. Yim (Kyung Hee University, Seoul, Korea). HDFs, isolated from foreskin [7], were cultured in Dulbecco's modified Eagle's medium containing 10\% fetal bovine serum (Life Technologies, Carlsbad, CA, USA), penicillin (100 units/mL) and streptomycin (100 units/mL) in a $5 \% \mathrm{CO}_{2}$ incubator [6].

\section{RNA isolation}

Total RNA was extracted from HDFs with Trizol (Life Technologies), purified with the addition of chloroform, and precipitated with the addition of isopropanol. The RNA concentration was determined by spectrophotometer and the quality of RNA was evaluated by OD 260/280 ratio and gel electrophoresis [8].

\section{cDNA microarray experiment}

The following procedures were carried out by Macrogen Co. (Seoul, Korea). Five hundred fifty nanograms of total RNA was reverse-transcribed to cDNA using a T7 oligo(dT) primer. Second-strand cDNA was synthesized, in vitro transcribed, and labeled with biotin-NTP. After purification, $750 \mathrm{ng}$ of labeled cRNA was hybridized to Illumina Human HT12 v.4 bead array (Illumina, San Diego, CA, USA) for 16-18 h at $58^{\circ} \mathrm{C}$. The array signal was detected by using Amersham fluorolink streptavidin-Cy3 (GE Healthcare Bio-Sciences, Little Chalfont, UK). Arrays were scanned with an Illumina bead array Reader confocal scanner. Array data were filtered by detection p-value $<0.05$ (similar to signal to noise). The average signal values of filtered genes were transformed by logarithm and normalized by the quantile method [8].

\section{Gene Set Enrichment Analysis (GSEA)}

The beta version of GSEA software and MSigDB 5.2 were downloaded from the Broad Institute (http://software. broadinstitute.org/gsea/index.jsp). GSEA was carried out as described previously [9]. Enrichment of gene sets was considered statistically significant if the normalized p-value was $<0.01$ and the false discovery rate (FDR) was $<0.20$.

\section{Results}

\section{Treatment of HDFs with COX inhibitors}

We have previously shown that among COX inhibitors studied, NS-398, a COX-2-selective inhibitor, inhibited replicative cellular senescence in HDFs as well as skin aging in hairless mice, whereas celecoxib, another COX-2-selective inhibitor, and aspirin, a non-selective COX inhibitor, accelerated the senescence and aging. At that time, we treated cells or skin with inhibitors every day for more than a month (Table 1) $[3,6]$.

To figure out causal factors for the senescence-modulating effect of the inhibitors, we treated HDFs with NS-398, celecoxib, aspirin, or dimethyl sulfoxide (DMSO) (the vehicle) every day for only 3 days in this study. The $\mathrm{IC}_{50}$ values have been reported for recombinant human COX-1 and COX-2 of NS-398 and celecoxib [10, 11], and for recombinant ovine COX-1 and COX-2 of aspirin [12]. In the

Table 1. Summary of senescence-modulating effect of COX inhibitors and used doses

\begin{tabular}{lllccccc}
\hline \multicolumn{2}{c}{ Inhibitors } & $\begin{array}{c}\text { Effect on HDF } \\
\text { senescence [6] }\end{array}$ & $\begin{array}{c}\text { Effect on skin } \\
\text { aging [3] }\end{array}$ & $\begin{array}{c}\mathrm{IC}_{50} \text { for COX-1 } \\
\text { [6] }\end{array}$ & $\begin{array}{c}\mathrm{IC}_{50} \text { for COX-2 } \\
\text { [6] }\end{array}$ & $\begin{array}{c}\text { Used doses in } \\
\text { this study }\end{array}$ \\
\hline \multirow{2}{*}{ COX-2-selective } & NS-398 & Delayed & Delayed & $75 \mu \mathrm{M}$ & $1.77 \mu \mathrm{M}$ & $20 \mu \mathrm{M}$ \\
\cline { 3 - 7 } Non-selective & Celecoxib & Accelerated & Accelerated & $15 \mu \mathrm{M}$ & $0.04 \mu \mathrm{M}$ & $0.5 \mu \mathrm{M}$ \\
\hline
\end{tabular}


case of NS-398 and celecoxib, we used approximately 10-fold higher concentration of $\mathrm{IC}_{50}$ to inhibit COX-2 catalytic activity sufficiently. NS-398 and celecoxib showed no acute cellular toxicity at this concentration. In the case of aspirin, however, we used $\mathrm{IC}_{50}$ because 10-fold higher concentration caused acute cellular toxicity (Table 1) [6].

\section{DNA microarray and GSEA}

We performed cDNA microarray experiment using RNA extracted from the drug-treated HDFs. Among 47,319 probe sets, 20,271 probe sets passed the criteria of the detection p-value $<0.05$. Unsupervised hierarchical cluster analysis showed that drug-treated cells were well segregated in the order of DMSO, NS-398, celecoxib, and aspirin (Fig. 1).

To figure out underlying mechanisms by which COX inhibitors modulate senescence, we performed GSEA using 17,777 probe sets having all information including gene symbols and gene descriptions. We sorted the data sets based on the value of ( $\left.\mathrm{I}_{\mathrm{NS}-398}-\mathrm{I}_{\mathrm{DMSO}}\right)$ for the comparison of

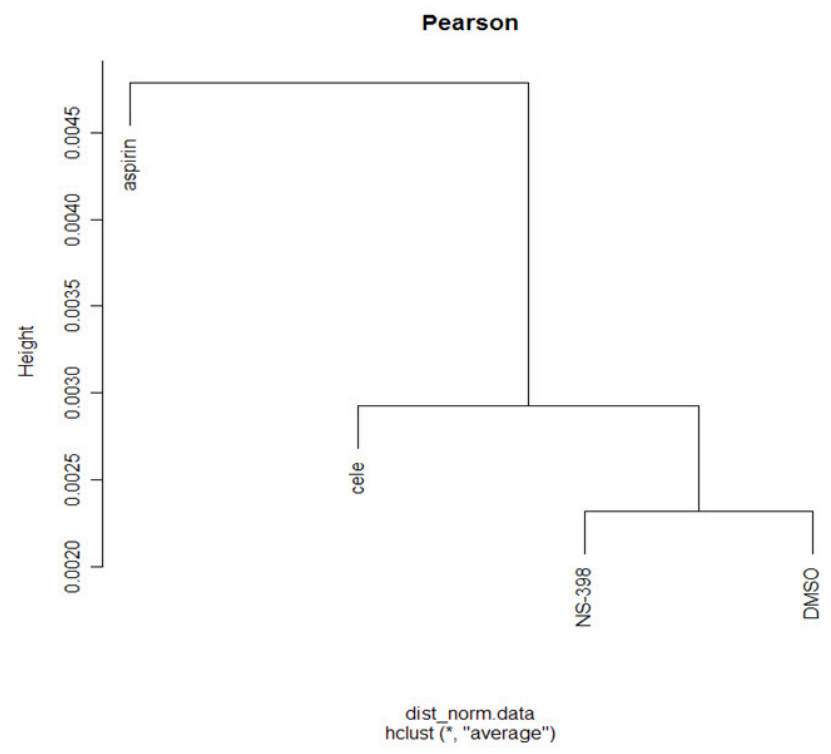

Fig. 1. Segregation between the drug-treated HDFs. Unsupervised hierarchical cluster analysis was done between four drug-treated HDFs using 20,271 probe sets with the detection p-value $<0.05$.
NS-398 versus DMSO; the value of ( $\left.\mathrm{I}_{\text {Celecoxib }}-\mathrm{I}_{\mathrm{DMSO}}\right)$ for the comparison of celecoxib versus DMSO; and the value of ( $\mathrm{I}_{\text {Aspirin }}-\mathrm{I}_{\mathrm{DMSO}}$ ) for the comparison of aspirin versus DMSO to rank the data sets as described previously [9].

We then tested (1) the Hallmark gene sets $(\mathrm{H})$; (2) gene sets regulating canonical pathways -i.e., Biocarta gene sets (C2:CP:BIOCARTA), Kyoto Encyclopedia of Genes and Genomes (KEGG) gene sets (C2:CP:KEGG), and Reactome gene sets (C2:CP:REACTOME); and (3) gene ontology gene sets-i.e., biological process gene sets (G5:BP), cellular component gene sets (G5:CC), and molecular function gene sets (G5:MF).

\section{NS-398 versus DMSO}

The analysis of NS-398 versus DMSO showed that two gene sets are enriched in NS-398-treated HDFs as compared with DMSO-treated HDFs. These gene sets consist of genes regulating the tumor necrosis factor beta receptor (TNFR2) pathway and the fructose and mannose metabolism (Table 2, Fig. 2A). Enriched genes in each pathway were shown in Supplementary Tables 1 and 2, and Supplementary Figs. 1 and 2.

On the other hand, four gene sets were enriched in DMSO-treated HDFs as compared with NS-398-treated HDFs: genes down-regulated in response to ultraviolet (UV) radiation, and genes regulating the protein secretion, the trefoil factor pathway and the receptor-regulated Smads (R-SMAD) binding (Table 3, Fig. 2B). Enriched genes in each gene set were shown in Supplementary Tables 3-6.

\section{Celecoxib versus DMSO}

The analysis of celecoxib versus DMSO showed that four gene sets were enriched in celecoxib-treated HDFs as compared with DMSO-treated HDFs. These gene sets consist of genes involved in the G2M checkpoint, E2F targets, $\gamma$ tubulin complex and the four way junction (Holliday junction) DNA binding (Table 4, Fig. 3A). Enriched genes in each gene set were shown in Supplementary Tables 7-10.

On the other hand, one gene set was enriched in DMSO-treated HDFs as compared with celecoxib-treated

Table 2. Enriched gene sets in NS-398-treated HDFs (NS-398 vs. DMSO)

\begin{tabular}{|c|c|c|c|}
\hline Name & NES & Normalized p-value & FDR q-value \\
\hline \multicolumn{4}{|l|}{ C2:CP:Biocarta } \\
\hline BIOCARTA_TNFR2_PATHWAY & 1.808 & 0.000 & 0.044 \\
\hline \multicolumn{4}{|l|}{ C2:CP:KEGG } \\
\hline KEGG_FRUCTOSE_AND_MANNOSE_METABOLISM & 1.721 & 0.009 & 0.159 \\
\hline
\end{tabular}

HDF, human dermal fibroblast; DMSO, dimethyl sulfoxide; NES, normalized enrichment score; FDR, false discovery rate. 
(A)

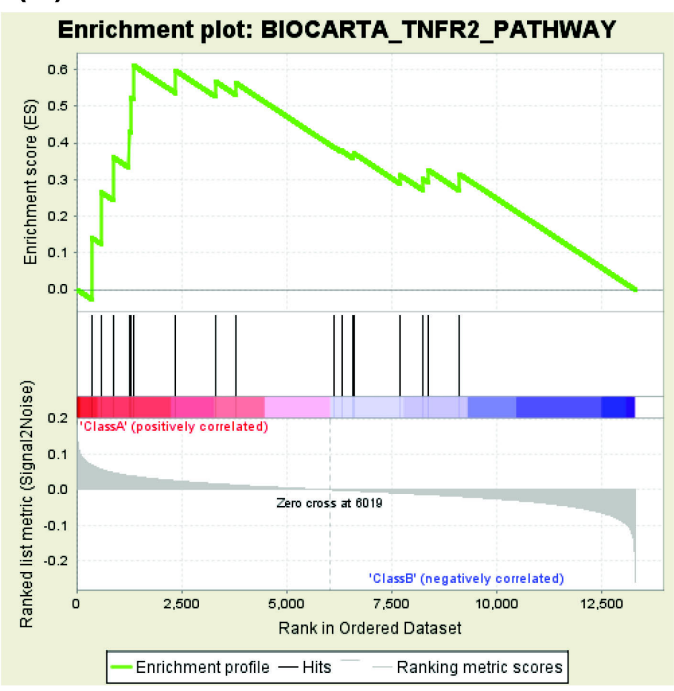

(B)

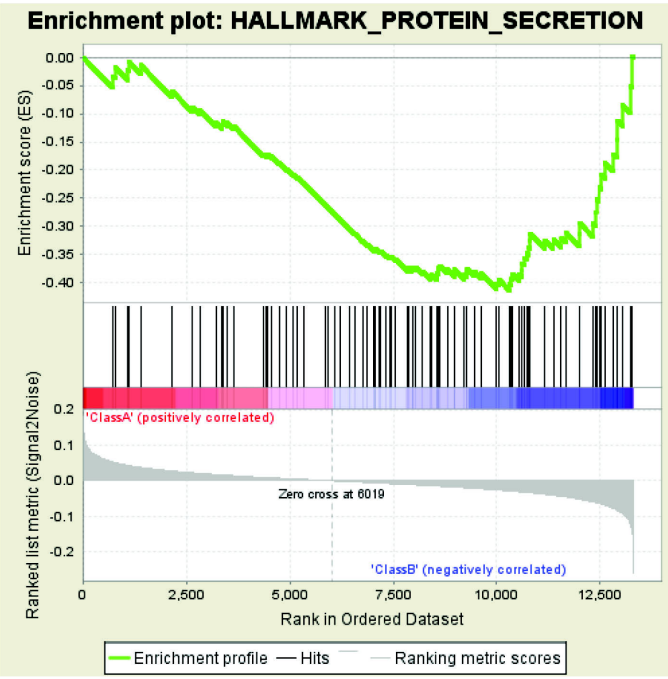

Fig. 2. Enrichment plots (NS-398 vs. DMSO). (A) A representative enriched gene set in NS-398-treated HDFs. (B) A representative enriched gene set in DMSO-treated HDFs. DMSO, dimethyl sulfoxide; HDF, human dermal fibroblast.

Table 3. Enriched gene sets in DMSO-treated HDFs (NS-398 vs. DMSO)

\begin{tabular}{|c|c|c|c|}
\hline Name & NES & Normalized p-value & FDR q-value \\
\hline \multicolumn{4}{|l|}{$\mathrm{H}$} \\
\hline HALLMARK_UV_RESPONSE_DN & -1.625 & 0.001 & 0.110 \\
\hline HALLMARK_PROTEIN_SECRETION & -1.545 & 0.004 & 0.140 \\
\hline \multicolumn{4}{|l|}{ C2:CP:Biocarta } \\
\hline BIOCARTA_TFF_PATHWAY & -1.799 & 0.000 & 0.160 \\
\hline \multicolumn{4}{|l|}{ C5:MF } \\
\hline GO_R_SMAD_BINDING & -1.823 & 0.000 & 0.166 \\
\hline
\end{tabular}

DMSO, dimethyl sulfoxide; HDF, human dermal fibroblast; NES, normalized enrichment score; FDR, false discovery rate.

Table 4. Enriched gene sets in celecoxib-treated HDFs (celecoxib vs. DMSO)

\begin{tabular}{|c|c|c|c|}
\hline Name & NES & Normalized $\mathrm{p}$-value & FDR q-value \\
\hline \multicolumn{4}{|l|}{$\mathrm{H}$} \\
\hline HALLMARK_G2M_CHECKPOINT & 1.642 & 0.000 & 0.074 \\
\hline HALLMARK_E2F_TARGETS & 1.427 & 0.007 & 0.164 \\
\hline \multicolumn{4}{|l|}{$\mathrm{C} 5: \mathrm{CC}--$} \\
\hline GO_GAMMA_TUBULIN_COMPLEX & 1.830 & 0.001 & 0.154 \\
\hline $\mathrm{C} 5: \mathrm{MF}^{-}$ & & & \\
\hline GO_FOUR_WAY_JUNCTION_DNA_BINDING & 1.884 & 0.002 & 0.104 \\
\hline
\end{tabular}

HDF, human dermal fibroblast; DMSO, dimethyl sulfoxide; NES, normalized enrichment score; FDR, false discovery rate.

HDFs. This gene set consists of genes regulating olfactory signaling pathway (Table 5, Fig. 3B). The list of enriched genes in this pathway was shown in Supplementary Table 11.

\section{Aspirin versus DMSO}

In the case of aspirin versus DMSO, four gene sets were enriched in aspirin-treated HDFs as compared with
DMSO-treated HDFs. These gene sets consist of genes involved in the protein secretion, keratin filament and intermediate filament, and genes down-regulated in response to UV radiation (Table 6, Fig. 4A). Enriched genes in each gene set were shown in Supplementary Tables 12-15.

On the other hand, three gene sets of $\mathrm{C} 2 \mathrm{CP}$ were enriched in DMSO-treated HDFs as compared with aspirin-treated 


\section{(A)}

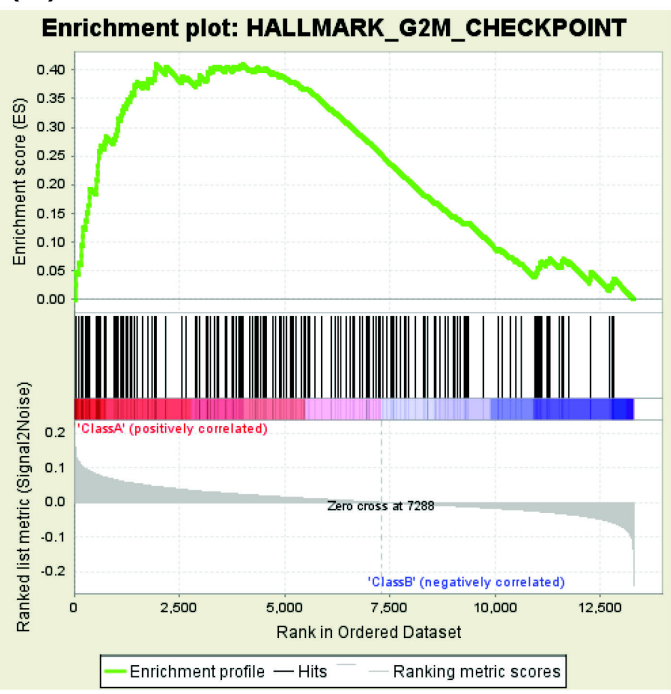

(B)

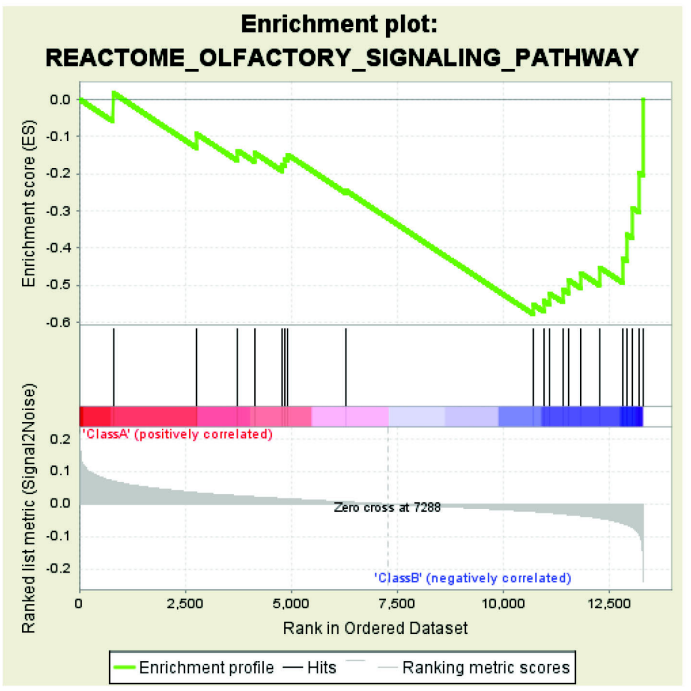

Fig. 3. Enrichment plots (celecoxib vs. DMSO). (A) A representative enriched gene set in celecoxib-treated HDFs. (B) The representative enriched gene set in DMSO-treated HDFs. DMSO, dimethyl sulfoxide; HDF, human dermal fibroblast.

Table 5. Enriched gene sets in DMSO-treated HDFs (celecoxib vs. DMSO) (C2:Reactome)

\begin{tabular}{cccc}
\hline Name & NES & Normalized p-value & FDR q-value \\
\hline REACTOME_OLFACTORY_SIGNALING_PATHWAY & -1.853 & 0.000 & 0.146 \\
\hline
\end{tabular}

DMSO, dimethyl sulfoxide; HDF, human dermal fibroblast; NES, normalized enrichment score; FDR, false discovery rate.

Table 6. Enriched gene sets in aspirin-treated HDFs (aspirin vs. DMSO)

\begin{tabular}{cccc}
\hline Name & NES & Normalized p-value & FDR q-value \\
\hline H & & & 0.000 \\
HALLMARK_PROTEIN_SECRETION & 1.764 & 0.000 & 0.037 \\
HALLMARK_UV_RESPONSE_DN & 1.495 & & 0.123 \\
C5:CC & & 0.000 & 0.000 \\
GO_KERATIN_FILAMENT & 2.204 & 0.000 & 0.008 \\
GO_INTERMEDIATE_FILAMENT & 1.960 & & \\
\hline
\end{tabular}

HDF, human dermal fibroblast; DMSO, dimethyl sulfoxide; NES, normalized enrichment score; FDR, false discovery rate.

HDFs: genes regulating prostate cancer, colorectal cancer, and cardiomyopathy (Table 7). In addition, 34 gene sets of C5:BP, three gene sets of C5:CC and five gene sets of C5:MF were enriched in DMSO-treated HDFs as compared with aspirin-treated HDFs. These gene sets consist of genes involved in embryonic development, negative regulation of protein localization to plasma membrane, DNA-dependent RNA transcription, cell differentiation, glutamate receptor binding, or Smad binding (Tables 7 and 8, Fig. 4B). Of note, the gene set involved in platelet aggregation was enriched in DMSO-treated HDFs as compared with aspirin-treated HDFs (Table 8, FDR, 0.179). Enriched genes in representative gene sets were shown in Supplementary Tables 16-22.

\section{Discussion}

Our data showed that NS-398 treatment up-regulated the gene set involved in the TNFR2 pathway (Table 2, Fig. 2A, Supplementary Table 1). This pathway is well known to activate the NF- $\kappa \mathrm{B}$ signaling that mediates cell proliferation, anti-apoptosis, inflammation, differentiation, or development (Supplementary Fig. 1) [13]. NF- $\kappa$ B, a transcription factor, has been reported to regulate cellular senescence though its role in the senescence is controversial. Overexpression of c-Rel resulted in premature senescence in normal human keratinocytes [14]. On the contrary, mouse embryonic fibroblasts from NF- $\kappa$ B1 knockout mice showed 


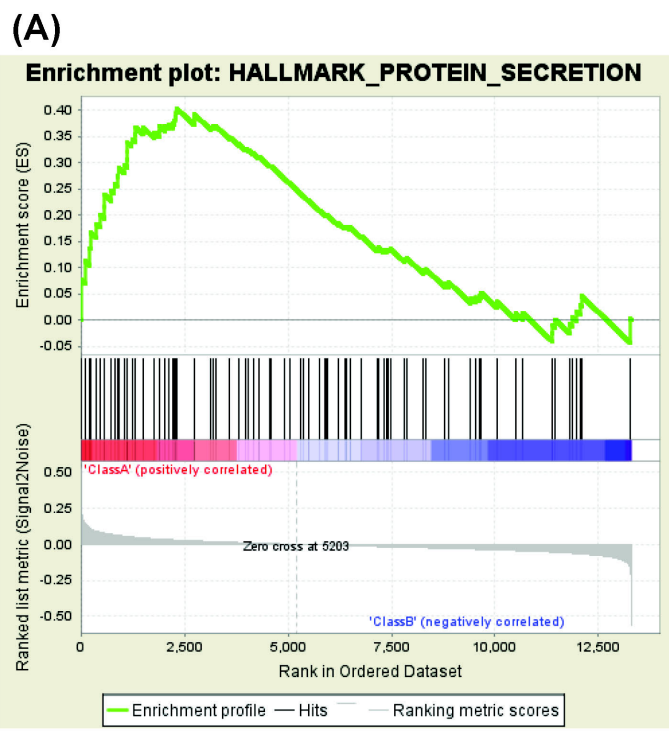

(B)

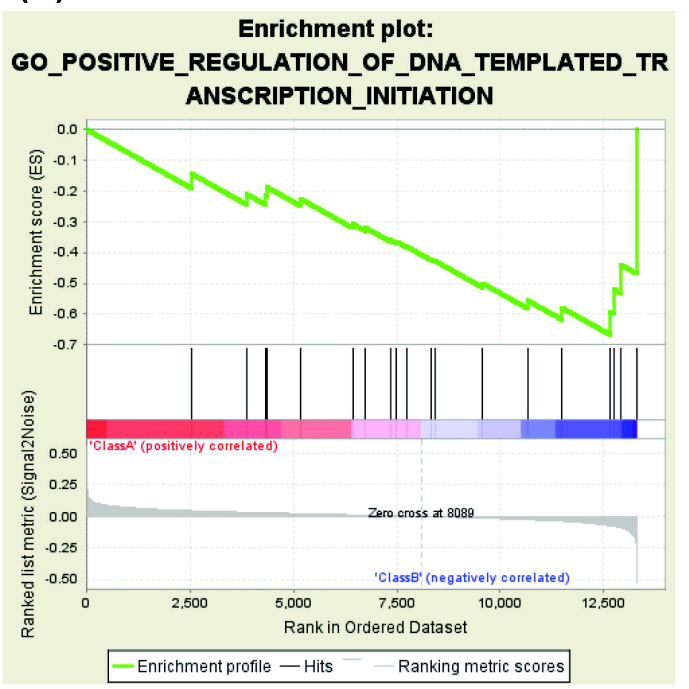

Fig. 4. Enrichment plots (aspirin vs. DMSO). (A) A representative enriched gene set in aspirin-treated HDFs. (B) A representative enriched gene set in DMSO-treated HDFs. DMSO, dimethyl sulfoxide; HDF, human dermal fibroblast.

Table 7. Enriched gene sets in DMSO-treated HDFs (aspirin vs. DMSO)

\begin{tabular}{|c|c|c|c|}
\hline Name & NES & Normalized p-value & FDR q-value \\
\hline \multicolumn{4}{|l|}{ C2:CP:KEGG } \\
\hline KEGG_PROSTATE_CANCER & -1.826 & 0.000 & 0.171 \\
\hline KEGG_COLORECTAL_CANCER & -1.742 & 0.000 & 0.172 \\
\hline KEGG_ARRHYTHMOG̈ENIC_RIGHT_VENTRICULAR_CARDIOMYOPATHY_ARVC & -1.635 & 0.006 & 0.199 \\
\hline \multicolumn{4}{|l|}{$\mathrm{C} 5: \mathrm{CC}$} \\
\hline GO_INTERCALATED_DISC & -1.930 & 0.000 & 0.077 \\
\hline GO_EUCHROMATIN & -1.963 & 0.000 & 0.120 \\
\hline GO_DENDRITIC_SHAFT & -1.757 & 0.008 & 0.199 \\
\hline \multicolumn{4}{|l|}{$\mathrm{C} 5: \overline{\mathrm{MF}} \quad-$} \\
\hline GO_IONOTROPIC_GLUTAMATE_RECEPTOR_BINDING & -1.947 & 0.003 & 0.062 \\
\hline GO_RNA_POLYMERASE_II_ACTIVATING_TRANSCRIPTION_FACTOR_BINDING & -1.922 & 0.003 & 0.062 \\
\hline GO_GLUTAMATE_RECEPTOR_BINDING & -1.952 & 0.000 & 0.077 \\
\hline GO_SMAD_BINDING & -1.981 & 0.000 & 0.085 \\
\hline GO_ACTIVATING_TRANSCRIPTION_FACTOR_BINDING & -2.032 & 0.000 & 0.088 \\
\hline
\end{tabular}

DMSO, dimethyl sulfoxide; HDF, human dermal fibroblast; NES, normalized enrichment score; FDR, false discovery rate.

enhanced cellular senescence [15]. In addition, siRNA against NF- $\kappa$ B2 or RelB induced premature senescence in HDFs in a p53-dependent manner [16]. These studies suggest that the anti-senescent effect of NS-398 might be attributable to a regulation of NF- $\kappa \mathrm{B}$ signaling.

NS-398 treatment also up-regulated the gene set involved in the fructose and mannose metabolism (Table 2, Supplementary Table 2). This metabolic pathway leads to enhanced glycolysis and N-glycan biosynthesis (Supplementary Fig. 2). Alterations of glucose metabolism have been reported in cellular senescence though the data is conflicting. In human mammary epithelial cells, B-Raf-induced premature senescence was associated with a reduction of glucose uptake, and overexpression of hexokinase 2 prevented the oncogeneinduced senescence [17]. On the contrary, glucose consumption and hexokinase activity were increased in senescent HDFs as compared to young HDFs [18]. These studies suggest that NS-398 might delay cellular senescence via regulation of glycolysis.

It is intriguing that the gene set involved in protein secretion is down-regulated by NS-398 treatment but is up-regulated by aspirin treatment (Tables 3 and 6, Figs. 2B and $4 \mathrm{~A}$, Supplementary Tables 4 and 12). It has been reported that cellular senescence is accompanied by an increase in the secretion of intercellular signaling molecules including interleukins, chemokines, growth factors, pro- 
Table 8. Enriched gene sets in DMSO-treated HDFs (aspirin vs. DMSO) (C5:BP)

\begin{tabular}{|c|c|c|c|}
\hline Name & NES & $\begin{array}{c}\text { Normalized } \\
\text { p-value }\end{array}$ & $\begin{array}{c}\text { FDR } \\
\text { q-value }\end{array}$ \\
\hline GO_GENITALIA_DEVELOPMENT & -2.072 & 0.000 & 0.036 \\
\hline GO_NEGATIVE_REGULATION_OF_PROTEIN_LOCALIZATION_TO_PLASMA_MEMBRANE & -2.076 & 0.000 & 0.041 \\
\hline GO_NEGATIVE_REGULATION_OF_PROTEIN_LOCALIZATION_TO_CELL_PERIPHERY & -2.077 & 0.000 & 0.049 \\
\hline GO_ENDOTHEL̄IAL_CELL_DEVELÖPMENT & -2.144 & 0.000 & 0.057 \\
\hline GO_ORGAN_FORMATION & -2.011 & 0.005 & 0.058 \\
\hline GO_BETA_CĀTENIN_TCF_COMPLEX_ASSEMBLY & -2.021 & 0.000 & 0.059 \\
\hline GO_REGŪLATION_ŌF_SISTER_CHRŌMATID_COHESION & -2.079 & 0.000 & 0.059 \\
\hline GO_POSITIVE_REGULĀTION_ŌF_DNA_TEMPLATED_TRANSCRIPTION_INITIATION & -2.101 & 0.000 & 0.061 \\
\hline GO_ESTABLISḦHMENT_OF_ENDOTTHELIAL_BARRIER ${ }^{-}$ & -2.154 & 0.000 & 0.098 \\
\hline GO_REGULATION_OF_HISTONE_METHYLATIION & -1.954 & 0.003 & 0.103 \\
\hline GO_CEREBRAL_CORTEXX_CELL_MIGRATION & -1.926 & 0.000 & 0.130 \\
\hline GO_REGULATIŌN_OF_C̄HROM̄ATIN_BINDING & -1.909 & 0.000 & 0.138 \\
\hline GO_HOMOTYPIC_CELL_CELL_ADHESION & -1.852 & 0.000 & 0.140 \\
\hline GO_REGULATION_OF_C̄HONDROCYTE_DIFFERENTIATION & -1.856 & 0.000 & 0.142 \\
\hline GO_REGULATION_OF_KERATINOCYTE_PROLIFERATION & -1.859 & 0.000 & 0.146 \\
\hline GO_EMBRYONIC_PATTERN_SPECIFICATION & -1.869 & 0.003 & 0.148 \\
\hline GO_EMBRYONIC_DIGIT_MŌRPHOGENESIS & -1.861 & 0.000 & 0.150 \\
\hline GO_EMBRYONIC_AXIS_SPECIFICATION & -1.870 & 0.000 & 0.156 \\
\hline GO_REGULATION_EF_HISTONE_H3_K4_METHYLATION & -1.825 & 0.008 & 0.162 \\
\hline GO_REGULATION_OF_O-OSTEOCLĀAST_DIFFERENTIATION & -1.830 & 0.003 & 0.163 \\
\hline GO_ENDOTHELIAL_CĒ_L_DIFFERENTIATTION & -1.870 & 0.000 & 0.166 \\
\hline GO_PALATE_DEVELOPMENT & -1.876 & 0.000 & 0.167 \\
\hline GO_POSITIVE_REGULATION_OF_EPITHELIAL_TO_MESENCHYMAL_TRANSITION & -1.814 & 0.003 & 0.171 \\
\hline GO_FOREBRĀNN_CELL_MIGRATIŌN & -1.809 & 0.003 & 0.172 \\
\hline GO_REGULATION_OF_CARTILAGE_DEVELOPMENT & -1.804 & 0.003 & 0.174 \\
\hline GO_POSITIVE_REGULLATTION_OF_MUUSCLE_TISSUE_DEVELOPMENT & -1.783 & 0.008 & 0.174 \\
\hline GO_ANTERIOR_POSTERIOR_AXIS_SPECIFICATION ${ }^{-}$ & -1.879 & 0.000 & 0.175 \\
\hline GO_POSITIVE_REGULATION_OF_TELOMERE_MAINTENANCE_VIA_TELOMERE_LENGTHENING & -1.786 & 0.000 & 0.176 \\
\hline GO_NEGATIVE__REGULATION̄_OF_EPITHELIĀ__CELL_DIFFERENTTIATTION & -1.796 & 0.008 & 0.179 \\
\hline GO_PLATELET_AGGREGATION & -1.788 & 0.008 & 0.179 \\
\hline GO_MYOBLAST_DIFFERENTIATION & -1.792 & 0.006 & 0.179 \\
\hline GO_ODONTOGENESIS & -1.772 & 0.000 & 0.185 \\
\hline GO_ODONTOGENESIS_OF_DENTIN_CONTAINING_TOOTH & -1.762 & 0.000 & 0.196 \\
\hline GO_REGULATION_OF_DNĀ_TEMPLĀTED_TRANSCRIPTION_INITIATION & -1.750 & 0.000 & 0.197 \\
\hline
\end{tabular}

DMSO, dimethyl sulfoxide; HDF, human dermal fibroblast; NES, normalized enrichment score; FDR, false discovery rate.

teases, and extracellular matrix proteins $[19,20]$. For example, production of interleukin-1, -6 , chemokine (C-C motif) ligand-1, -2, -3, -7, -8, -12, -13, -16, -20, -26, chemokine (C-X-C motif) ligand- $1,-2,-4,-5,-6,-8$, insulin-like growth factor binding protein-2, $-3,-4,-5,-6,-7$, connective tissue growth factor, granulocyte-macrophage colony-stimulating factor, granulocyte colony stimulating factor, matrix metalloproteinase-1, -3, -10, plasminogen activator inhibitor 1 , or fibronectin increased in senescent HDFs as compared to in young HDFs [21]. Ectopic expression of chemokine receptors such as CXCR1 or CXCR2 induced premature senescence in HDFs [22]. Extracellular matrix from young HDFs restored senescent HDFs to an apparently youthful state [23]. In addition, there is a report that p16-induced senescence is accompanied by an increase in the glucose-stimulated insulin secretion in mouse and human pancreatic beta cells [24]. These studies suggest that regulation of protein secretion might be an important common mechanism by which NS-398 delays but aspirin accelerates cellular senescence.

In addition to the up-regulation of protein secretion, aspirin down-regulated gene sets involved in DNA-dependent RNA transcription (Table 7, FDR, 0.062 and 0.088; Table 8, FDR, 0.061 and 0.197; Fig. 4B). Compatible with these results, a cDNA microarray study reported that genes involved in transcription were down-regulated specifically during senescence in HDFs [25]. In addition, there is a report that RNA transcription was decreased in aged rat 
brain as compared to in young rat brain [26]. Therefore, aspirin might accelerate cellular senescence by downregulation of DNA-dependent RNA transcription.

It is well known that aspirin inhibits platelet aggregation and thereby thrombus formation [27]. Consistent with this, our data showed that the gene set involved in platelet aggregation was down-regulated by aspirin treatment (Table 8, FDR, 0.179).

Cyclin-dependent kinase inhibitors (CKIs) are categorized into two families, that is, the Ink 4 family including p15, p16, $\mathrm{p} 18$, and $\mathrm{p} 19$, and the Cip/Kip family including p21, p27, and $\mathrm{p} 57$. It has been reported that these CKIs are actively involved in cellular senescence. For example, ectopic expression of $\mathrm{p} 15, \mathrm{p} 16, \mathrm{p} 19, \mathrm{p} 21$, or $\mathrm{p} 27$ was reported to induce premature senescence in HDFs [28, 29]. According to our data, celecoxib treatment up-regulated gene sets relating G2M checkpoint and E2F targets (Table 4, Fig. 3A). In addition, $C D K N 1 B$ encoding p27 and $C D K N 2 C$ encoding p18 were enriched in both gene sets (Supplementary Table 7, Running enrichment score [ES], 0.410 and 0.274; Supplementary Table 8, Running ES, 0.299 and 0.193). These data suggest that celecoxib might accelerate cellular senescence through up-regulation of CKIs.

Collectively, our results suggest that COX inhibitors modulate cellular senescence by different mechanisms though they have the anti-catalytic activity commonly. We believe that our study will provide useful information to understand senescence-modulating mechanisms of COX inhibitors.

\section{Supplementary materials}

Supplementary data including 22 tables and two figures can be found with this article online http://www.genominfo. org/src/sm/gni-15-56-s001.pdf.

\section{Acknowledgments}

This research was supported by the Basic Science Research Program through the NRF funded by the Ministry of Education, Science and Technology (NRF-2016R1A2B4012817) and by the 2016 Research Grant from Kangwon National University (No. 520160232).

\section{References}

1. Ricciotti E, FitzGerald GA. Prostaglandins and inflammation. Arterioscler Thromb Vasc Biol 2011;31:986-1000.

2. Han JA, Kim JI, Ongusaha PP, Hwang DH, Ballou LR, Mahale A, et al. P53-mediated induction of Cox-2 counteracts p53- or genotoxic stress-induced apoptosis. EMBO J 2002;21:5635-5644.
3. Lee ME, Kim SR, Lee S, Jung YJ, Choi SS, Kim WJ, et al. Cyclooxygenase-2 inhibitors modulate skin aging in a catalytic activity-independent manner. Exp Mol Med 2012;44:536-544.

4. Flower RJ. The development of COX2 inhibitors. Nat Rev Drug Discov 2003;2:179-191.

5. Chung HY, Cesari M, Anton S, Marzetti E, Giovannini S, Seo AY, et al. Molecular inflammation: underpinnings of aging and age-related diseases. Ageing Res Rev 2009;8:18-30.

6. Kim SR, Park JH, Lee ME, Park JS, Park SC, Han JA. Selective COX-2 inhibitors modulate cellular senescence in human dermal fibroblasts in a catalytic activity-independent manner. Mech Ageing Dev 2008;129:706-713.

7. Yeo EJ, Hwang YC, Kang CM, Kim IH, Kim DI, Parka JS, et al. Senescence-like changes induced by hydroxyurea in human diploid fibroblasts. Exp Gerontol 2000;35:553-571.

8. Han JA, Kim JY, Kim JI. Analysis of gene expression in cyclooxygenase-2-overexpressed human osteosarcoma cell lines. Genomics Inform 2014;12:247-253.

9. Subramanian A, Tamayo P, Mootha VK, Mukherjee S, Ebert BL, Gillette MA, et al. Gene set enrichment analysis: a knowledge-based approach for interpreting genome-wide expression profiles. Proc Natl Acad Sci U S A 2005;102:15545-15550.

10. Barnett J, Chow J, Ives D, Chiou M, Mackenzie R, Osen E, et al. Purification, characterization and selective inhibition of human prostaglandin $\mathrm{G} / \mathrm{H}$ synthase 1 and 2 expressed in the baculovirus system. Biochim Biophys Acta 1994;1209:130-139.

11. Penning TD, Talley JJ, Bertenshaw SR, Carter JS, Collins PW, Docter S, et al. Synthesis and biological evaluation of the 1,5-diarylpyrazole class of cyclooxygenase-2 inhibitors: identification of 4-[5-(4-methylphenyl)-3-(trifluoromethyl)-1Hpyrazol-1-yl]benze nesulfonamide (SC-58635, celecoxib). J Med Chem 1997;40:1347-1365.

12. Johnson JL, Wimsatt J, Buckel SD, Dyer RD, Maddipati KR. Purification and characterization of prostaglandin $\mathrm{H}$ synthase-2 from sheep placental cotyledons. Arch Biochem Biophys 1995;324:26-34.

13. Gerondakis S, Fulford TS, Messina NL, Grumont RJ. NF- $\kappa$ B control of T cell development. Nat Immunol 2014;15:15-25.

14. Bernard D, Gosselin K, Monte D, Vercamer C, Bouali F, Pourtier A, et al. Involvement of Rel/nuclear factor-kappaB transcription factors in keratinocyte senescence. Cancer Res 2004;64:472-481.

15. Bernal GM, Wahlstrom JS, Crawley CD, Cahill KE, Pytel P, Liang $\mathrm{H}$, et al. Loss of Nfkb1 leads to early onset aging. Aging (Albany NY) 2014;6:931-943.

16. Iannetti A, Ledoux AC, Tudhope SJ, Sellier H, Zhao B, Mowla $\mathrm{S}$, et al. Regulation of $\mathrm{p} 53$ and $\mathrm{Rb}$ links the alternative NF- $\kappa \mathrm{B}$ pathway to EZH2 expression and cell senescence. PLoS Genet 2014;10:e1004642.

17. Gitenay D, Wiel C, Lallet-Daher H, Vindrieux D, Aubert S, Payen $\mathrm{L}$, et al. Glucose metabolism and hexosamine pathway regulate oncogene-induced senescence. Cell Death Dis 2014;5:e1089.

18. Zwerschke W, Mazurek S, Stöckl P, Hütter E, Eigenbrodt E, Jansen-Dürr P. Metabolic analysis of senescent human fibroblasts reveals a role for AMP in cellular senescence. Biochem $J$ 2003;376 (Pt 2):403-411.

19. Coppe JP, Patil CK, Rodier F, Krtolica A, Beauséjour CM, 
Parrinello S, et al. A human-like senescence-associated secretory phenotype is conserved in mouse cells dependent on physiological oxygen. PLoS One 2010;5:e9188.

20. Freund A, Orjalo AV, Desprez PY, Campisi J. Inflammatory networks during cellular senescence: causes and consequences. Trends Mol Med 2010;16:238-246.

21. Coppé JP, Desprez PY, Krtolica A, Campisi J. The senescence-associated secretory phenotype: the dark side of tumor suppression. Annu Rev Pathol 2010;5:99-118.

22. Acosta JC, O'Loghlen A, Banito A, Guijarro MV, Augert A, Raguz $\mathrm{S}$, et al. Chemokine signaling via the CXCR2 receptor reinforces senescence. Cell 2008;133:1006-1018.

23. Choi HR, Cho KA, Kang HT, Lee JB, Kaeberlein M, Suh Y, et al. Restoration of senescent human diploid fibroblasts by modulation of the extracellular matrix. Aging Cell 2011;10:148-157.

24. Helman A, Klochendler A, Azazmeh N, Gabai Y, Horwitz E, Anzi S, et al. p16(Ink4a)-induced senescence of pancreatic be- ta cells enhances insulin secretion. Nat Med 2016;22:412-420.

25. Zhang H, Pan KH, Cohen SN. Senescence-specific gene expression fingerprints reveal cell-type-dependent physical clustering of up-regulated chromosomal loci. Proc Natl Acad Sci U S A 2003;100:3251-3256.

26. Lindholm DB. Decreased transcription of neuronal polyadenylated RNA during senescence in nuclei from rat brain cortex. J Neurochem 1986;47:1503-1506.

27. Smith JB, Willis AL. Aspirin selectively inhibits prostaglandin production in human platelets. Nat New Biol 1971;231:235-237.

28. McConnell BB, Starborg M, Brookes S, Peters G. Inhibitors of cyclin-dependent kinases induce features of replicative senescence in early passage human diploid fibroblasts. Curr Biol 1998;8:351-354.

29. Wei W, Hemmer RM, Sedivy JM. Role of p14(ARF) in replicative and induced senescence of human fibroblasts. Mol Cell Biol 2001;21:6748-6757. 


\title{
SUPPLEMENTARY INFORMATION
}

\section{Analysis of Gene Expression in Human Dermal Fibroblasts Treated with Senescence-Modulating COX Inhibitors}

\author{
Jeong A. Han ${ }^{1 *}$, Jong-II Kim ${ }^{2,3,4 * *}$
}

${ }^{1}$ Department of Biochemistry and Molecular Biology, Kangwon National University School of Medicine, Chuncheon 24341, Korea, ${ }^{2}$ Department of Biochemistry and Molecular Biology, Seoul National University College of Medicine, Seoul 03080, Korea, ${ }^{3}$ Cancer Research Institute, Seoul National University College of Medicine, Seoul 03080, Korea, ${ }^{4}$ Department of Biomedical Sciences, Seoul National University Graduate School, Seoul 03080, Korea 


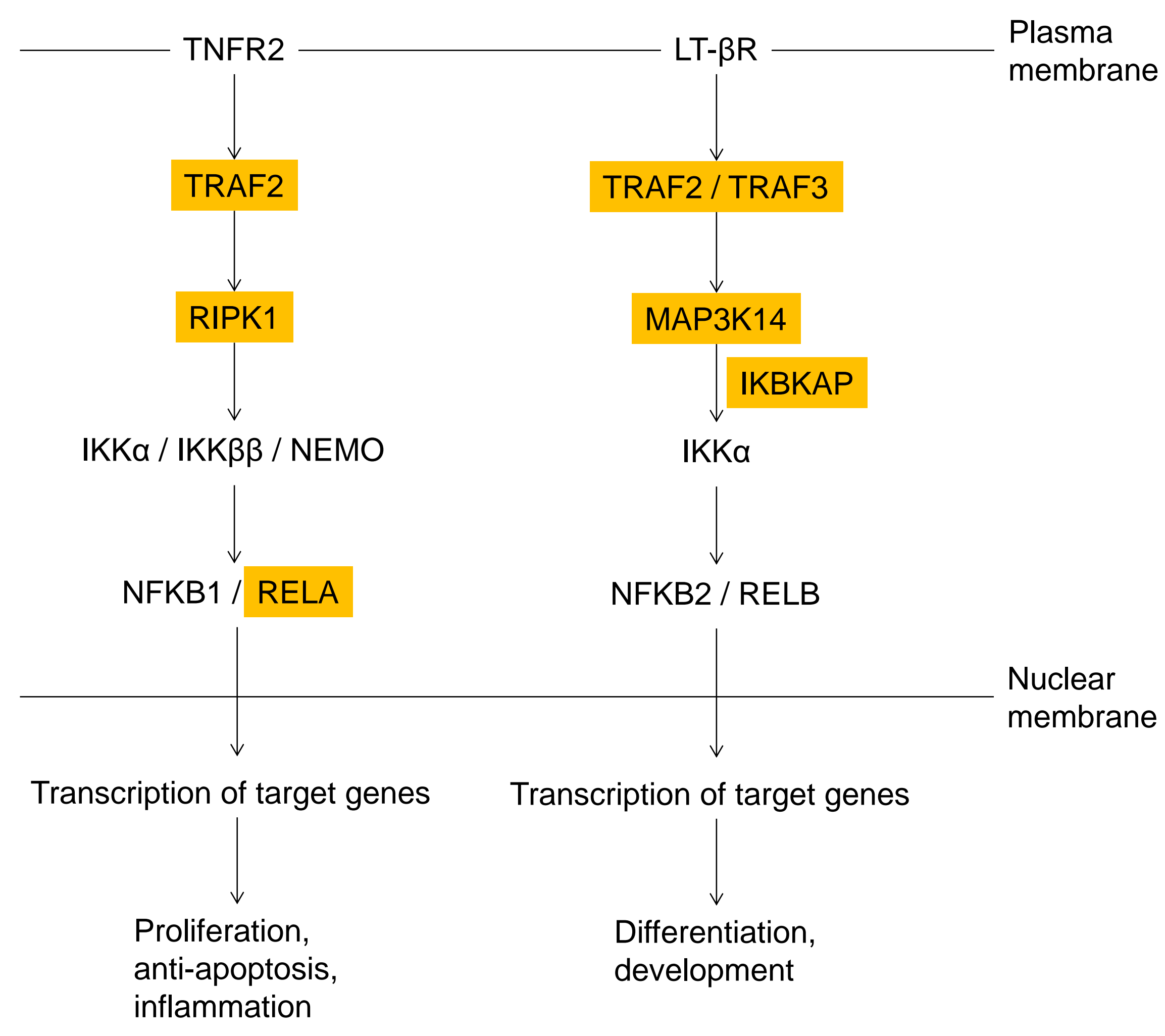

Supplementary Fig. 1. BIOCARTA_TNFR2 PATHWAY. Enriched genes were highlighted in orange color. 


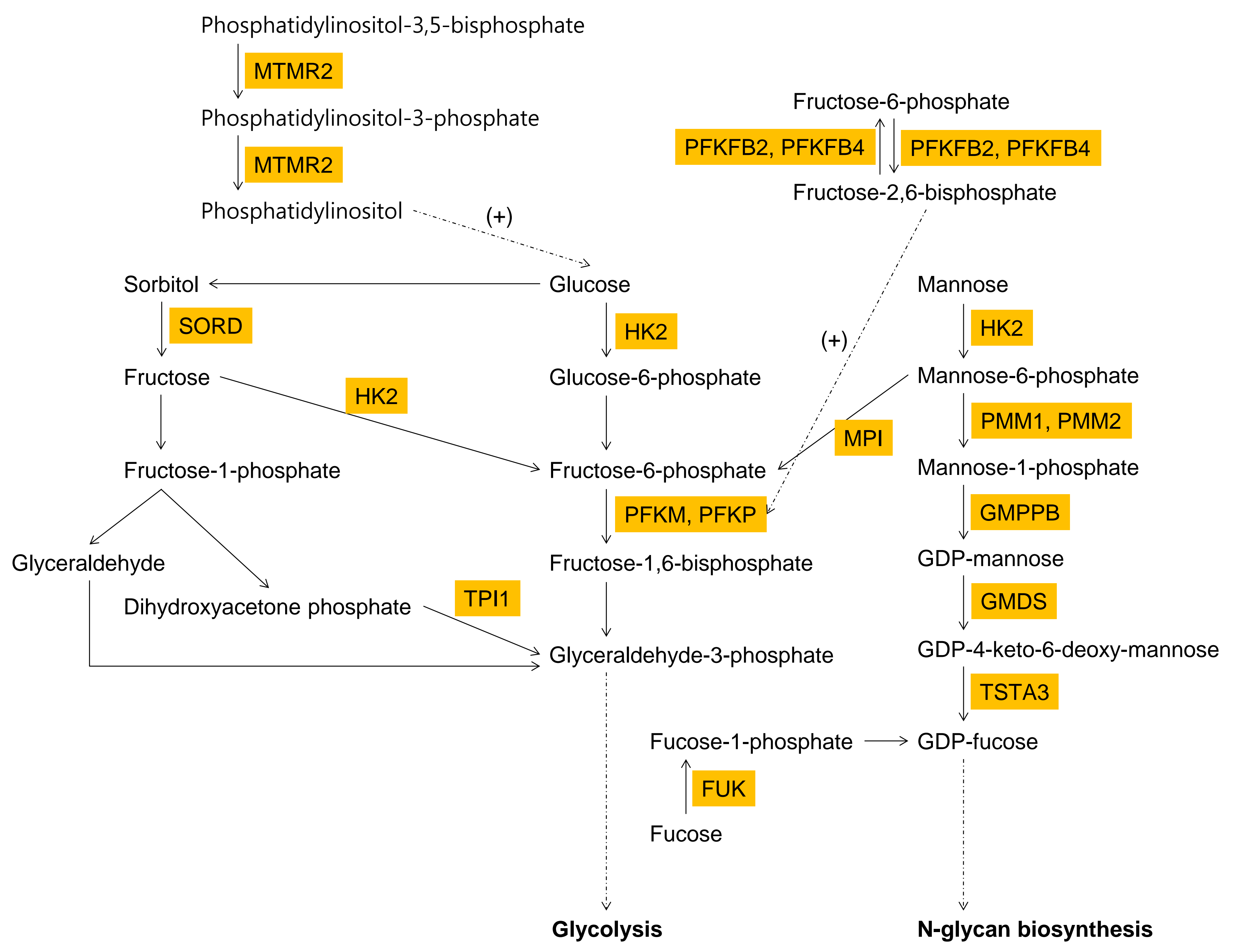

Supplementary Fig. 2. KEGG_FRUCTOSE_AND_MANNOSE_METABOLISM. Enriched genes were highlighted in orange color. 
Supplementary Table 1. Enriched genes of BIOCARTA_TNFR2_PATHWAY in NS-398-treated HDFs (NS-398 vs. DMSO)

\begin{tabular}{llr}
\hline Symbol & Description & $\begin{array}{l}\text { Running } \\
\text { ES }\end{array}$ \\
\hline TRAF3 & TNF receptor-associated factor 3 & 0.612 \\
$I K B K A P$ & Inhibitor of kappa light polypeptide gene enhancer in B-cells, kinase complex-associated protein & 0.522 \\
$T R A F 2$ & TNF receptor-associated factor 2 & 0.430 \\
RIPK1 & Receptor (TNFRSF)-interacting serine-threonine kinase 1 & 0.361 \\
RELA & v-rel avian reticuloendotheliosis viral oncogene homolog A & 0.266 \\
$M A P 3 K 14$ & Mitogen-activated protein kinase kinase kinase 14 & 0.141 \\
\hline
\end{tabular}

HDF, human dermal fibroblast; DMSO, dimethyl sulfoxide; ES, enrichment score. 
Supplementary Table 2. Enriched genes of KEGG_FRUCTOSE_AND_MANNOSE_METABOLISM in NS-398-treated HDFs (NS-398 vs.

\section{DMSO)}

\begin{tabular}{llr}
\hline Symbol & Description & $\begin{array}{l}\text { Running } \\
\text { ES }\end{array}$ \\
\hline$M T M R 2$ & Myotubularin related protein 2 & 0.535 \\
$P M M 1$ & Phosphomannomutase 1 & 0.534 \\
$P M M 2$ & Phosphomannomutase 2 & 0.521 \\
SORD & Sorbitol dehydrogenase & 0.518 \\
TPI1 & Triosephosphate isomerase 1 & 0.518 \\
GMDS & GDP-mannose 4,6-dehydratase & 0.515 \\
PFKFB4 & 6-Phosphofructo-2-kinase/fructose-2,6-biphosphatase 4 & 0.502 \\
GMPPB & GDP-mannose pyrophosphorylase B & 0.484 \\
$P F K F B 2$ & 6-Phosphofructo-2-kinase/fructose-2,6-biphosphatase 2 & 0.443 \\
FUK & Fucokinase & 0.400 \\
$H K 2$ & Hexokinase 2 & 0.362 \\
$M P I$ & Mannose phosphate isomerase & 0.290 \\
$P F K M$ & Phosphofructokinase, muscle & 0.225 \\
$P F K P$ & Phosphofructokinase, platelet & 0.143 \\
$T S T A 3$ & Tissue specific transplantation antigen P35B & 0.063 \\
\hline
\end{tabular}

HDF, human dermal fibroblast; DMSO, dimethyl sulfoxide; ES, enrichment score. 
Supplementary Table 3. Enriched genes of HALLMARK_UV_RESPONSE_DN in DMSO-treated HDFs (NS-398 vs. DMSO)

\begin{tabular}{|c|c|c|}
\hline Symbol & Description & Running ES \\
\hline$B C K D H B$ & Branched chain keto acid dehydrogenase E1, beta polypeptide & -0.405 \\
\hline$M A P 1 B$ & Microtubule-associated protein 1B & -0.405 \\
\hline HAS2 & Hyaluronan synthase 2 & -0.401 \\
\hline$F 3$ & Coagulation factor III (thromboplastin, tissue factor) & -0.396 \\
\hline$S R I$ & Sorcin & -0.393 \\
\hline$A T P 2 B 4$ & ATPase, $\mathrm{Ca}++$ transporting, plasma membrane 4 & -0.390 \\
\hline$V L D L R$ & Very low density lipoprotein receptor & -0.387 \\
\hline NRP1 & Neuropilin 1 & -0.386 \\
\hline$I G F 1 R$ & PREDICTED: Homo sapiens hypothetical protein MGC18216 (MGC18216), mRNA. & -0.385 \\
\hline FBLN5 & Fibulin 5 & -0.384 \\
\hline SMAD3 & SMAD family member 3 & -0.384 \\
\hline$S L C 7 A 1$ & Solute carrier family 7 (cationic amino acid transporter, $y+$ system), member 1 & -0.382 \\
\hline PTPRM & Protein tyrosine phosphatase, receptor type, $\mathrm{M}$ & -0.381 \\
\hline INSIG1 & Insulin induced gene 1 & -0.380 \\
\hline$D D A H 1$ & Dimethylarginine dimethylaminohydrolase 1 & -0.378 \\
\hline$D A B 2$ & Dab, mitogen-responsive phosphoprotein, homolog 2 (Drosophila) & -0.378 \\
\hline$C D C 42 B P A$ & CDC42 binding protein kinase alpha (DMPK-like) & -0.378 \\
\hline$A B C C 1$ & ATP-binding cassette, sub-family C (CFTR/MRP), member 1 & -0.377 \\
\hline YTHDC1 & YTH domain containing 1 & -0.376 \\
\hline SNAI2 & Snail family zinc finger 2 & -0.373 \\
\hline MMP16 & Matrix metallopeptidase 16 (membrane-inserted) & -0.371 \\
\hline ICA1 & Islet cell autoantigen $1,69 \mathrm{kDa}$ & -0.368 \\
\hline EFEMP1 & EGF containing fibulin-like extracellular matrix protein 1 & -0.364 \\
\hline$P M P 22$ & Peripheral myelin protein 22 & -0.357 \\
\hline
\end{tabular}




\begin{tabular}{|c|c|c|}
\hline SERPINE1 & Serpin peptidase inhibitor, clade E (nexin, plasminogen activator inhibitor type 1 ), member 1 & -0.349 \\
\hline$M G L L$ & Monoglyceride lipase & -0.343 \\
\hline WDR37 & WD repeat domain 37 & -0.341 \\
\hline$B D N F$ & Brain-derived neurotrophic factor & -0.338 \\
\hline SIPAIL1 & Signal-induced proliferation-associated 1 like 1 & -0.335 \\
\hline$A D O R A 2 B$ & Adenosine $\mathrm{A} 2 \mathrm{~b}$ receptor & -0.333 \\
\hline GCNT1 & Glucosaminyl (N-acetyl) transferase 1 , core 2 & -0.333 \\
\hline CITED2 & Cbp/p300-interacting transactivator, with Glu/Asp-rich carboxy-terminal domain, 2 & -0.330 \\
\hline KCNMA1 & Potassium channel, calcium activated large conductance subfamily $\mathrm{M}$ alpha, member 1 & -0.325 \\
\hline NR1D2 & Nuclear receptor subfamily 1 , group D, member 2 & -0.321 \\
\hline PTGFR & Prostaglandin F receptor (FP) & -0.316 \\
\hline TFPI & Tissue factor pathway inhibitor (lipoprotein-associated coagulation inhibitor) & -0.307 \\
\hline BHLHE40 & Basic helix-loop-helix family, member e40 & -0.304 \\
\hline$A T X N 1$ & Ataxin 1 & -0.304 \\
\hline$A D D 3$ & Adducin 3 (gamma) & -0.299 \\
\hline$D Y R K 1 A$ & Dual-specificity tyrosine-(Y)-phosphorylation regulated kinase $1 \mathrm{~A}$ & -0.293 \\
\hline RND3 & Rho family GTPase 3 & -0.289 \\
\hline ANXA4 & Annexin A4 & -0.281 \\
\hline$P P A R G$ & Peroxisome proliferator-activated receptor gamma & -0.271 \\
\hline$M A G I 2$ & Membrane associated guanylate kinase, WW and PDZ domain containing 2 & -0.258 \\
\hline GRK5 & G protein-coupled receptor kinase 5 & -0.246 \\
\hline LPHN2 & Latrophilin 2 & -0.236 \\
\hline$L P A R 1$ & Lysophosphatidic acid receptor 1 & -0.236 \\
\hline$A T P 2 B 1$ & ATPase, $\mathrm{Ca}++$ transporting, plasma membrane 1 & -0.225 \\
\hline PEX14 & Peroxisomal biogenesis factor 14 & -0.223 \\
\hline$A C V R 2 A$ & Activin A receptor, type IIA & -0.209 \\
\hline$A G G F 1$ & Angiogenic factor with $G$ patch and FHA domains 1 & -0.194 \\
\hline
\end{tabular}


Tight junction protein 1 
Supplementary Table 4. Enriched genes of HALLMARK_PROTEIN_SECRETION in DMSO-treated HDFs (NS-398 vs. DMSO)

\begin{tabular}{|c|c|c|}
\hline Symbol & Description & Running ES \\
\hline YIPF6 & Yip1 domain family, member 6 & -0.402 \\
\hline ICA1 & Islet cell autoantigen $1,69 \mathrm{kDa}$ & -0.394 \\
\hline$I G F 2 R$ & Insulin-like growth factor 2 receptor & -0.385 \\
\hline$A R F G A P 3$ & ADP-ribosylation factor GTPase activating protein 3 & -0.384 \\
\hline ERGIC3 & ERGIC and golgi 3 & -0.377 \\
\hline TMED2 & Transmembrane emp24 domain trafficking protein 2 & -0.365 \\
\hline$G A L C$ & Galactosylceramidase & -0.357 \\
\hline TOM1L1 & Target of myb1 (chicken)-like 1 & -0.347 \\
\hline$S N A P 23$ & Synaptosomal-associated protein, $23 \mathrm{kDa}$ & -0.338 \\
\hline$S T X 7$ & Syntaxin 7 & -0.326 \\
\hline MON2 & MON2 homolog (S. cerevisiae) & -0.325 \\
\hline KIF1B & Kinesin family member 1B & -0.324 \\
\hline$A R F G E F 1$ & ADP-ribosylation factor guanine nucleotide-exchange factor 1 (brefeldin A-inhibited) & -0.321 \\
\hline RERl & Retention in endoplasmic reticulum sorting receptor 1 & -0.314 \\
\hline$R A B 5 A$ & RAB5A, member RAS oncogene family & -0.313 \\
\hline CLTC & Clathrin, heavy chain $(\mathrm{Hc})$ & -0.311 \\
\hline SGMS1 & Sphingomyelin synthase 1 & -0.294 \\
\hline$V A M P 4$ & Vesicle-associated membrane protein 4 & -0.294 \\
\hline TMED10 & Transmembrane emp24-like trafficking protein 10 (yeast) & -0.274 \\
\hline CTSC & Cathepsin C & -0.252 \\
\hline DST & Dystonin & -0.231 \\
\hline$L A M P 2$ & Lysosomal-associated membrane protein 2 & -0.208 \\
\hline DOPEY1 & Dopey family member 1 & -0.187 \\
\hline$A D A M 10$ & ADAM metallopeptidase domain 10 & -0.171 \\
\hline
\end{tabular}




\begin{tabular}{llr} 
SCAMP1 & Secretory carrier membrane protein 1 & -0.145 \\
ARFIP1 & ADP-ribosylation factor interacting protein 1 & -0.113 \\
SEC31A & SEC31 homolog A (S. cerevisiae) & -0.085 \\
$A R F 1$ & ADP-ribosylation factor 1 & -0.050 \\
SEC22B & SEC22 vesicle trafficking protein homolog B (S. cerevisiae) (gene/pseudogene) & 0.002 \\
\hline
\end{tabular}

DMSO, dimethyl sulfoxide; ES, enrichment score. 
Supplementary Table 5. Enriched genes of BIOCARTA_TFF_PATHWAY in DMSO-treated HDFs (NS-398 vs. DMSO)

\begin{tabular}{llr}
\hline Symbol & Description & $\begin{array}{l}\text { Running } \\
\text { ES }\end{array}$ \\
\hline APAF1 & Apoptotic peptidase activating factor 1 & -0.582 \\
CASP9 & Caspase 9, apoptosis-related cysteine peptidase & -0.522 \\
SOS1 & Son of sevenless homolog 1 (Drosophila) & -0.432 \\
$C Y C S$ & Cytochrome c, somatic & -0.251 \\
CTNNB1 & Catenin (cadherin-associated protein), beta 1, 88kDa & 0.001 \\
\hline
\end{tabular}

DMSO, dimethyl sulfoxide; ES, enrichment score. 
Supplementary Table 6. Enriched genes of GO_R_SMAD_BINDING in DMSO-treated HDFs (NS-398 vs. DMSO)

\begin{tabular}{llr}
\hline Symbol & Description & Running ES \\
\hline$P P M 1 A$ & Protein phosphatase, Mg2+/Mn2+ dependent, 1A & -0.558 \\
$Z E B 2$ & Zinc finger E-box binding homeobox 2 & -0.420 \\
$R A N B P 3$ & RAN binding protein 3 & -0.266 \\
$C T N N B 1$ & Catenin (cadherin-associated protein), beta 1, 88kDa & 0.001 \\
\hline
\end{tabular}

DMSO, dimethyl sulfoxide; HDF, human dermal fibroblast; ES, enrichment score. 
Supplementary Table 7. Enriched genes of HALLMARK_G2M_CHECKPOINT in celecoxib-treated HDFs (celecoxib vs. DMSO)

\begin{tabular}{|c|c|c|}
\hline Symbol & Decription & Running ES \\
\hline$B C L 3$ & B-cell CLL/lymphoma 3 & 0.410 \\
\hline$C D K N 1 B$ & Cyclin-dependent kinase inhibitor 1B (p27, Kip1) & 0.410 \\
\hline WHSC1 & Wolf-Hirschhorn syndrome candidate 1 & 0.408 \\
\hline SUV39H1 & Suppressor of variegation 3-9 homolog 1 (Drosophila) & 0.407 \\
\hline$P D S 5 B$ & PDS5 cohesin associated factor B & 0.406 \\
\hline CENPE & Centromere protein $\mathrm{E}, 312 \mathrm{kDa}$ & 0.406 \\
\hline$C D C 45$ & Cell division cycle 45 & 0.406 \\
\hline CENPF & Centromere protein F, $350 / 400 \mathrm{kDa}$ & 0.406 \\
\hline KIF15 & Kinesin family member 15 & 0.405 \\
\hline TACC3 & Transforming, acidic coiled-coil containing protein 3 & 0.405 \\
\hline TOP $2 A$ & Topoisomerase (DNA) II alpha 170kDa & 0.405 \\
\hline KPNB1 & Karyopherin (importin) beta 1 & 0.405 \\
\hline$D D X 39 A$ & DEAD (Asp-Glu-Ala-Asp) box polypeptide 39A & 0.404 \\
\hline$U C K 2$ & Uridine-cytidine kinase 2 & 0.403 \\
\hline SYNCRIP & Synaptotagmin binding, cytoplasmic RNA interacting protein & 0.403 \\
\hline NEK2 & NIMA-related kinase 2 & 0.402 \\
\hline TRAIP & TRAF interacting protein & 0.401 \\
\hline$R A D 23 B$ & RAD23 homolog B (S. cerevisiae) & 0.400 \\
\hline ORC5 & Origin recognition complex, subunit 5 & 0.400 \\
\hline$P B K$ & PDZ binding kinase & 0.398 \\
\hline TMPO & Thymopoietin & 0.398 \\
\hline$S L C 7 A 1$ & Solute carrier family 7 (cationic amino acid transporter, $y+$ system), member 1 & 0.397 \\
\hline CUL5 & Cullin 5 & 0.396 \\
\hline KIF $5 B$ & Kinesin family member 5B & 0.392 \\
\hline$H N R N P U$ & Heterogeneous nuclear ribonucleoprotein U (scaffold attachment factor A) & 0.390 \\
\hline
\end{tabular}




\begin{tabular}{|c|c|c|}
\hline EWSRl & EWS RNA-binding protein 1 & 0.388 \\
\hline$P O L Q$ & Polymerase (DNA directed), theta & 0.388 \\
\hline TFDP1 & Transcription factor $\mathrm{Dp}-1$ & 0.388 \\
\hline$S L C 38 A 1$ & Solute carrier family 38 , member 1 & 0.387 \\
\hline$H 2 A F Z$ & $\mathrm{H} 2 \mathrm{~A}$ histone family, member $\mathrm{Z}$ & 0.385 \\
\hline$U B E 2 C$ & Ubiquitin-conjugating enzyme $\mathrm{E} 2 \mathrm{C}$ & 0.385 \\
\hline NUSAP1 & Nucleolar and spindle associated protein 1 & 0.384 \\
\hline$Z A K$ & Sterile alpha motif and leucine zipper containing kinase AZK & 0.383 \\
\hline$C D K 1$ & Cyclin-dependent kinase 1 & 0.383 \\
\hline PLK1 & Polo-like kinase 1 & 0.381 \\
\hline$L M N B 1$ & Lamin B1 & 0.380 \\
\hline$D R 1$ & Down-regulator of transcription 1, TBP-binding (negative cofactor 2) & 0.380 \\
\hline KIF11 & Kinesin family member 11 & 0.377 \\
\hline$P T T G 3 P$ & Pituitary tumor-transforming 3 , pseudogene & 0.376 \\
\hline STIL & SCL/TAL1 interrupting locus & 0.376 \\
\hline$C K S 2$ & CDC28 protein kinase regulatory subunit 2 & 0.373 \\
\hline$D B F 4$ & DBF4 zinc finger & 0.366 \\
\hline$R B L 1$ & Retinoblastoma-like 1 & 0.361 \\
\hline CUL4A & Cullin 4A & 0.353 \\
\hline SNRPD1 & Small nuclear ribonucleoprotein D1 polypeptide $16 \mathrm{kDa}$ & 0.350 \\
\hline$A M D 1$ & Adenosylmethionine decarboxylase 1 & 0.342 \\
\hline$S F P Q$ & Splicing factor proline/glutamine-rich & 0.336 \\
\hline EZH2 & Enhancer of zeste 2 polycomb repressive complex 2 subunit & 0.330 \\
\hline SAP30 & Sin3A-associated protein, $30 \mathrm{kDa}$ & 0.321 \\
\hline$H 2 A F V$ & $\mathrm{H} 2 \mathrm{~A}$ histone family, member $\mathrm{V}$ & 0.315 \\
\hline CDC6 & Cell division cycle 6 & 0.305 \\
\hline PURA & Purine-rich element binding protein $\mathrm{A}$ & 0.296 \\
\hline
\end{tabular}




\begin{tabular}{llr}
$R A S A L 2$ & RAS protein activator like 2 & 0.288 \\
$M Y C$ & V-myc avian myelocytomatosis viral oncogene homolog & 0.284 \\
$M N A T 1$ & MNAT CDK-activating kinase assembly factor 1 & 0.281 \\
$C D K N 2 C$ & Cyclin-dependent kinase inhibitor 2C (p18, inhibits CDK4) & 0.274 \\
$H M G N 2$ & High mobility group nucleosomal binding domain 2 & 0.268 \\
$R A D 21$ & RAD21 homolog (S. pombe) & 0.259 \\
G3BP1 & GTPase activating protein (SH3 domain) binding protein 1 & 0.246 \\
$M T F 2$ & Metal response element binding transcription factor 2 & 0.233 \\
$Y T H D C 1$ & YTH domain containing 1 & 0.221 \\
$B U B 1$ & BUB1 mitotic checkpoint serine/threonine kinase & 0.209 \\
$F B X O 5$ & F-box protein 5 & 0.196 \\
$T T K$ & TTK protein kinase & 0.193 \\
KPNA2 & Karyopherin alpha 2 (RAG cohort 1, importin alpha 1) \\
$S M C 2$ & Structural maintenance of chromosomes 2 & 0.179 \\
$H I F 1 A$ & Hypoxia inducible factor 1, alpha subunit (basic helix-loop-helix transcription factor) & 0.165 \\
$O D F 2$ & Outer dense fiber of sperm tails 2 & 0.152 \\
$S L C 12 A 2$ & Solute carrier family 12 (sodium/potassium/chloride transporter), member 2 \\
$R A C G A P 1$ & Rac GTPase activating protein 1 & 0.137 \\
$M A D 2 L 1$ & MAD2 mitotic arrest deficient-like 1 (yeast) & 0.125 \\
$X P O 1$ & Exportin 1 & 0.109 \\
$H M M R$ & Hyaluronan-mediated motility receptor (RHAMM) & 0.095 \\
$B U B 3$ & BUB3 mitotic checkpoint protein & 0.077 \\
$C D C 25 B$ & Cell division cycle 25B & 0.063 \\
\hline
\end{tabular}

HDF, human dermal fibroblast; DMSO, dimethyl sulfoxide; ES, enrichment score. 
Supplementary Table 8. Enriched genes of HALLMARK E2F_TARGETS in celecoxib-treated HDFs (celecoxib vs. DMSO)

\begin{tabular}{|c|c|c|}
\hline Symbol & Description & $\begin{array}{l}\text { Running } \\
\text { ES }\end{array}$ \\
\hline SUV39H1 & Suppressor of variegation 3-9 homolog 1 (Drosophila) & 0.357 \\
\hline PCNA & Proliferating cell nuclear antigen & 0.353 \\
\hline TACC3 & Transforming, acidic coiled-coil containing protein 3 & 0.350 \\
\hline TOP $2 A$ & Topoisomerase (DNA) II alpha 170kDa & 0.350 \\
\hline PDS5B & PDS5 cohesin associated factor B & 0.347 \\
\hline$S P C 25$ & SPC25, NDC80 kinetochore complex component & 0.346 \\
\hline CENPM & Centromere protein $\mathrm{M}$ & 0.343 \\
\hline HELLS & Helicase, lymphoid-specific & 0.343 \\
\hline GINS4 & GINS complex subunit 4 (Sld5 homolog) & 0.342 \\
\hline TMPO & Thymopoietin & 0.339 \\
\hline SYNCRIP & Synaptotagmin binding, cytoplasmic RNA interacting protein & 0.339 \\
\hline RAD51C & RAD51 paralog C & 0.339 \\
\hline NUP205 & Nucleoporin $205 \mathrm{kDa}$ & 0.338 \\
\hline$T B R G 4$ & Transforming growth factor beta regulator 4 & 0.338 \\
\hline CENPE & Centromere protein $\mathrm{E}, 312 \mathrm{kDa}$ & 0.337 \\
\hline CHEK2 & Checkpoint kinase 2 & 0.336 \\
\hline$S L B P$ & Stem-loop binding protein & 0.336 \\
\hline$D L G A P 5$ & Discs, large (Drosophila) homolog-associated protein 5 & 0.334 \\
\hline PMS2 & PMS2 postmeiotic segregation increased 2 (S. cerevisiae) & 0.334 \\
\hline$D D X 39 A$ & DEAD (Asp-Glu-Ala-Asp) box polypeptide 39A & 0.331 \\
\hline$H 2 A F Z$ & H2A histone family, member Z & 0.330 \\
\hline$P L K 1$ & Polo-like kinase 1 & 0.326 \\
\hline$C B X 5$ & Chromobox homolog 5 & 0.326 \\
\hline
\end{tabular}




\begin{tabular}{|c|c|c|}
\hline POLDI & Polymerase (DNA directed), delta 1, catalytic subunit & 0.323 \\
\hline$P S I P 1$ & PC4 and SFRS1 interacting protein 1 & 0.322 \\
\hline$L M N B 1$ & Lamin B1 & 0.320 \\
\hline$D U T$ & Deoxyuridine triphosphatase & 0.319 \\
\hline NUDT21 & Nudix (nucleoside diphosphate linked moiety X)-type motif 21 & 0.318 \\
\hline PRPS1 & Phosphoribosyl pyrophosphate synthetase 1 & 0.318 \\
\hline$R P A 3$ & Replication protein $\mathrm{A} 3,14 \mathrm{kDa}$ & 0.315 \\
\hline$P P M 1 D$ & Protein phosphatase, $\mathrm{Mg} 2+/ \mathrm{Mn} 2+$ dependent, $1 \mathrm{D}$ & 0.313 \\
\hline$D C K$ & Deoxycytidine kinase & 0.309 \\
\hline ING3 & Inhibitor of growth family, member 3 & 0.309 \\
\hline TIPIN & TIMELESS interacting protein & 0.308 \\
\hline NME1 & NME/NM23 nucleoside diphosphate kinase 1 & 0.307 \\
\hline DCLRE1B & DNA cross-link repair 1B & 0.306 \\
\hline$C D K 1$ & Cyclin-dependent kinase 1 & 0.304 \\
\hline$D E K$ & DEK proto-oncogene & 0.304 \\
\hline$L Y A R$ & Ly1 antibody reactive & 0.303 \\
\hline$C D K N 1 B$ & Cyclin-dependent kinase inhibitor 1B (p27, Kip1) & 0.299 \\
\hline RADl & RAD1 checkpoint DNA exonuclease & 0.298 \\
\hline MCM4 & Minichromosome maintenance complex component 4 & 0.293 \\
\hline USP1 & Ubiquitin specific peptidase 1 & 0.290 \\
\hline$D E P D C 1$ & DEP domain containing 1 & 0.290 \\
\hline$E Z H 2$ & Enhancer of zeste 2 polycomb repressive complex 2 subunit & 0.290 \\
\hline$C K S 2$ & CDC28 protein kinase regulatory subunit 2 & 0.285 \\
\hline BRMSIL & Breast cancer metastasis-suppressor 1-like & 0.282 \\
\hline PSMC3IP & PSMC3 interacting protein & 0.281 \\
\hline SMC6 & Structural maintenance of chromosomes 6 & 0.275 \\
\hline$E E D$ & Embryonic ectoderm development & 0.265 \\
\hline
\end{tabular}




\begin{tabular}{|c|c|c|}
\hline$H M G B 2$ & High mobility group box 2 & 0.259 \\
\hline$T U B G 1$ & Tubulin, gamma 1 & 0.252 \\
\hline MTHFD2 & Methylenetetrahydrofolate dehydrogenase (NADP+ dependent) 2, methenyltetrahydrofolate cyclohydrolase & 0.248 \\
\hline CCP110 & Centriolar coiled coil protein $110 \mathrm{kDa}$ & 0.236 \\
\hline$N B N$ & Nibrin & 0.226 \\
\hline MYC & v-myc avian myelocytomatosis viral oncogene homolog & 0.215 \\
\hline$B R C A 1$ & Breast cancer 1 , early onset & 0.204 \\
\hline$C D K N 2 C$ & Cyclin-dependent kinase inhibitor $2 \mathrm{C}$ ( 18 , inhibits CDK4) & 0.193 \\
\hline$S M C 3$ & Structural maintenance of chromosomes 3 & 0.182 \\
\hline$R A D 21$ & RAD21 homolog (S. pombe) & 0.177 \\
\hline$M M S 22 L$ & MMS22-like, DNA repair protein & 0.167 \\
\hline DIAPH3 & Diaphanous-related formin 3 & 0.154 \\
\hline LUC7L3 & LUC7-like 3 (S. cerevisiae) & 0.141 \\
\hline MSH2 & mutS homolog 2 & 0.128 \\
\hline NAP1L1 & Nucleosome assembly protein 1 -like 1 & 0.114 \\
\hline TCF19 & Transcription factor 19 & 0.108 \\
\hline KPNA2 & Karyopherin alpha 2 (RAG cohort 1 , importin alpha 1$)$ & 0.093 \\
\hline$R A C G A P 1$ & Rac GTPase activating protein 1 & 0.088 \\
\hline$M A D 2 L 1$ & MAD2 mitotic arrest deficient-like 1 (yeast) & 0.074 \\
\hline XPO1 & Exportin 1 & 0.055 \\
\hline$H M M R$ & Hyaluronan-mediated motility receptor (RHAMM) & 0.041 \\
\hline$C D C 25 B$ & Cell division cycle $25 \mathrm{~B}$ & 0.026 \\
\hline
\end{tabular}

HDF, human dermal fibroblast; DMSO, dimethyl sulfoxide; ES, enrichment score. 
Supplementary Table 9. Enriched genes of GO_GAMMA_TUBULIN_COMPLEX in Celecoxib-treated HDFs (celecoxib vs. DMSO)

\begin{tabular}{llr}
\hline Symbol & Description & $\begin{array}{l}\text { Running } \\
\text { ES }\end{array}$ \\
\hline$T U B G 1$ & Tubulin, gamma 1 & 0.685 \\
$M Z T 1$ & Mitotic spindle organizing protein 1 & 0.595 \\
BRCA1 & Breast cancer 1, early onset & 0.490 \\
CEP290 & Centrosomal protein 290kDa & 0.391 \\
ZNF365 & Zinc finger protein 365 & 0.293 \\
TOPORS & Topoisomerase I binding, arginine/serine-rich, E3 ubiquitin protein ligase & 0.172 \\
\hline
\end{tabular}

HDF, human dermal fibroblast; DMSO, dimethyl sulfoxide; ES, enrichment score. 
Supplementary Table 10. Enriched genes of GO_FOUR_WAY_JUNCTION_DNA_BINDING in celecoxib-treated HDFs (celecoxib vs.

DMSO)

\begin{tabular}{llr}
\hline Symbol & Description & Running ES \\
\hline$M E N 1$ & Multiple endocrine neoplasia I & 0.723 \\
$D M C 1$ & DNA meiotic recombinase 1 & 0.640 \\
$H M G B 1$ & High mobility group box 1 & 0.534 \\
$H M G B 2$ & High mobility group box 2 & 0.434 \\
$R A D 51 D$ & RAD51 paralog D & 0.330 \\
$Y Y 1$ & YY1 transcription factor & 0.209 \\
$M S H 2$ & mutS homolog 2 & 0.110 \\
\hline
\end{tabular}

HDF, human dermal fibroblast; DMSO, dimethyl sulfoxide; ES, enrichment score. 
Supplementary Table 11. Enriched genes of REACTOME_OLFACTORY_SIGNALING_PATHWAY in DMSO-treated HDFs (celecoxib vs. DMSO)

\begin{tabular}{llr}
\hline Symbol & Description & Running ES \\
\hline GNB1 & Guanine nucleotide binding protein (G protein), beta polypeptide 1 & -0.553 \\
OR1L8 & Olfactory receptor, family 1, subfamily L, member 8 & -0.543 \\
OR10W1 & Olfactory receptor, family 10, subfamily W, member 1 & -0.523 \\
OR4C15 & Olfactory receptor, family 4, subfamily C, member 15 & -0.513 \\
OR5AS1 & Olfactory receptor, family 5, subfamily AS, member 1 13 & -0.486 \\
OR9A4 & Olfactory receptor, family 9, subfamily A, member 4 & -0.468 \\
OR8B12 & Olfactory receptor, family 8, subfamily B, member 12 & -0.452 \\
OR4C12 & Olfactory receptor, family 4, subfamily C, member 12 & -0.429 \\
OR4A16 & Olfactory receptor, family 4, subfamily A, member 16 & -0.364 \\
OR1D4 & Homo sapiens olfactory receptor, family 1, subfamily D, member 4 (OR1D4), mRNA. & -0.293 \\
OR3A2 & Olfactory receptor, family 3, subfamily A, member 2 & -0.199 \\
OR10H4 & Olfactory receptor, family 10, subfamily H, member 4 & 0.000 \\
\hline DISO,
\end{tabular}

DMSO, dimethyl sulfoxide; HDF, human dermal fibroblast; ES, enrichment score. 
Supplementary Table 12. Enriched genes of HALLMARK PROTEIN_SECRETION in aspirin-treated HDFs (aspirin vs. DMSO)

\begin{tabular}{|c|c|c|}
\hline Symbol & Description & Running ES \\
\hline$A R F G A P 3$ & ADP-ribosylation factor GTPase activating protein 3 & 0.403 \\
\hline CTSC & Cathepsin C & 0.395 \\
\hline YIPF6 & Yip1 domain family, member 6 & 0.389 \\
\hline STX7 & Syntaxin 7 & 0.381 \\
\hline$P A M$ & Peptidylglycine alpha-amidating monooxygenase & 0.375 \\
\hline VAMP7 & Vesicle-associated membrane protein 7 & 0.373 \\
\hline$S C A M P 1$ & Secretory carrier membrane protein 1 & 0.370 \\
\hline CLTC & Clathrin, heavy chain $(\mathrm{Hc})$ & 0.369 \\
\hline$I G F 2 R$ & Insulin-like growth factor 2 receptor & 0.368 \\
\hline GLA & Galactosidase, alpha & 0.367 \\
\hline SNX2 & Sorting nexin 2 & 0.360 \\
\hline AP3S1 & Adaptor-related protein complex 3 , sigma 1 subunit & 0.358 \\
\hline SGMS1 & Sphingomyelin synthase 1 & 0.355 \\
\hline DOPEY1 & Dopey family member 1 & 0.346 \\
\hline TMED10 & Transmembrane emp24-like trafficking protein 10 (yeast) & 0.338 \\
\hline$A P 1 G 1$ & Adaptor-related protein complex 1, gamma 1 subunit & 0.322 \\
\hline TMED2 & Transmembrane emp24 domain trafficking protein 2 & 0.307 \\
\hline$M 6 P R$ & Mannose-6-phosphate receptor (cation dependent) & 0.295 \\
\hline$A R F G E F 1$ & ADP-ribosylation factor guanine nucleotide-exchange factor 1 (brefeldin A-inhibited) & 0.290 \\
\hline STAM & Signal transducing adaptor molecule (SH3 domain and ITAM motif) 1 & 0.274 \\
\hline MON2 & MON2 homolog (S. cerevisiae) & 0.260 \\
\hline$A D A M 10$ & ADAM metallopeptidase domain 10 & 0.246 \\
\hline$N A P G$ & N-Ethylmaleimide-sensitive factor attachment protein, gamma & 0.238 \\
\hline$R A B 5 A$ & RAB5A, member RAS oncogene family & 0.216 \\
\hline
\end{tabular}




\begin{tabular}{llr} 
TOM1L1 & Target of myb1 (chicken)-like 1 & 0.201 \\
GBF1 & Golgi brefeldin A resistant guanine nucleotide exchange factor 1 & 0.183 \\
$D S T$ & Dystonin & 0.167 \\
LMAN1 & Lectin, mannose-binding, 1 & 0.137 \\
$A B C A 1$ & ATP-binding cassette, sub-family A (ABC1), member 1 & 0.112 \\
SEC 22B & SEC22 vesicle trafficking protein homolog B (S. cerevisiae) (gene/pseudogene) & 0.076 \\
\hline
\end{tabular}

HDF, human dermal fibroblast; DMSO, dimethyl sulfoxide; ES, enrichment score. 
Supplementary Table 13. Enriched genes of HALLMARK_UV_RESPONSE_DN in aspirin-treated HDFs (aspirin vs. DMSO)

\begin{tabular}{|c|c|c|}
\hline Symbol & Description & Running ES \\
\hline PLCB4 & Phospholipase C, beta 4 & 0.318 \\
\hline$C D K N 1 B$ & Cyclin-dependent kinase inhibitor 1B (p27, Kip1) & 0.318 \\
\hline PTGFR & Prostaglandin $\mathrm{F}$ receptor $(\mathrm{FP})$ & 0.316 \\
\hline COL11A1 & Collagen, type XI, alpha 1 & 0.315 \\
\hline ZMIZ1 & Zinc finger, MIZ-type containing 1 & 0.313 \\
\hline SYNE1 & Spectrin repeat containing, nuclear envelope 1 & 0.312 \\
\hline$P P A R G$ & Peroxisome proliferator-activated receptor gamma & 0.311 \\
\hline$V L D L R$ & Very low density lipoprotein receptor & 0.309 \\
\hline MTA1 & Metastasis associated 1 & 0.308 \\
\hline SNAI2 & Snail family zinc finger 2 & 0.306 \\
\hline$S D C 2$ & Syndecan 2 & 0.304 \\
\hline SIPA1L1 & Signal-induced proliferation-associated 1 like 1 & 0.303 \\
\hline$L D L R$ & Low density lipoprotein receptor & 0.302 \\
\hline$D D A H 1$ & Dimethylarginine dimethylaminohydrolase 1 & 0.302 \\
\hline$A P B B 2$ & Amyloid beta (A4) precursor protein-binding, family B, member 2 & 0.302 \\
\hline$R B P M S$ & RNA binding protein with multiple splicing & 0.301 \\
\hline FAM179B & Family with sequence similarity 179 , member B & 0.299 \\
\hline PDLIM5 & PDZ and LIM domain 5 & 0.297 \\
\hline SERPINE1 & Serpin peptidase inhibitor, clade E (nexin, plasminogen activator inhibitor type 1), member 1 & 0.297 \\
\hline MAGI2 & Membrane associated guanylate kinase, WW and PDZ domain containing 2 & 0.297 \\
\hline PRDM2 & PR domain containing 2, with ZNF domain & 0.296 \\
\hline$T G F B R 3$ & Transforming growth factor, beta receptor III & 0.290 \\
\hline SPOP & Speckle-type POZ protein & 0.279 \\
\hline$K A L R N$ & Kalirin, RhoGEF kinase & 0.269 \\
\hline
\end{tabular}




\begin{tabular}{llr}
$I R S 1$ & Insulin receptor substrate 1 & 0.258 \\
$D Y R K 1 A$ & Dual-specificity tyrosine-(Y)-phosphorylation regulated kinase 1A & 0.248 \\
$A G G F 1$ & Angiogenic factor with G patch and FHA domains 1 & 0.246 \\
$P E X 14$ & Peroxisomal biogenesis factor 14 & 0.237 \\
$R N D 3$ & Rho family GTPase 3 & 0.230 \\
$L P H N 2$ & Latrophilin 2 & 0.216 \\
$B H L H E 40$ & Basic helix-loop-helix family, member e40 & 0.208 \\
$A T R X$ & Alpha thalassemia/mental retardation syndrome X-linked & 0.197 \\
$B M P R 1 A$ & Bone morphogenetic protein receptor, type IA & 0.180 \\
$Y T H D C 1$ & YTH domain containing 1 & 0.164 \\
$M A P 1 B$ & Microtubule-associated protein 1B & 0.149 \\
$T J P 1$ & Tight junction protein 1 & 0.133 \\
$I T G B 3$ & Integrin, beta 3 (platelet glycoprotein IIIa, antigen CD61) & 0.122 \\
$N R 1 D 2$ & Nuclear receptor subfamily 1, group D, member 2 & 0.112 \\
$A B C C 1$ & ATP-binding cassette, sub-family C (CFTR/MRP), member 1 & 0.098 \\
$I N S I G 1$ & Insulin induced gene 1 & 0.076 \\
$N E K 7$ & NIMA-related kinase 7 & 0.049 \\
$R A S A 2$ & RAS p21 protein activator 2 & 0.021 \\
\hline
\end{tabular}

HDF, human dermal fibroblast; DMSO, dimethyl sulfoxide; ES, enrichment score. 
Supplementary Table 14. Enriched genes of GO_KERATIN_FILAMENT in aspirin-treated HDFs (aspirin vs. DMSO)

\begin{tabular}{llr}
\hline Symbol & Description & $\begin{array}{l}\text { Running } \\
\text { ES }\end{array}$ \\
\hline KRTAP9-4 & Keratin associated protein 9-4 & 0.788 \\
KRT80 & Keratin 80, type II & 0.761 \\
KRTAP1-4 & PREDICTED: Homo sapiens similar to keratin associated protein 1.6 (LOC730743), mRNA. & 0.732 \\
KRT7 & Keratin 7, type II & 0.690 \\
CSNK1A1 & Casein kinase 1, alpha 1 & 0.667 \\
KRT14 & Keratin 14, type I & 0.605 \\
KRTAP4-8 & PREDICTED: Homo sapiens keratin associated protein 4-8, transcript variant 2 (KRTAP4-8), mRNA. \\
KRT86 & Keratin 86, type II & 0.544 \\
KRTAP2-1 & Keratin associated protein 2-1 & 0.481 \\
KRT81 & Keratin 81, type II & 0.428 \\
KRTAP4-12 & Keratin associated protein 4-12 & 0.331 \\
KRT8 & Keratin 8, type II & 0.227 \\
\hline
\end{tabular}

HDF, human dermal fibroblast; DMSO, dimethyl sulfoxide; ES, enrichment score. 
Supplementary Table 15. Enriched genes of GO_INTERMEDIATE_FILAMENT in aspirin-treated HDFs (aspirin vs. DMSO)

\begin{tabular}{llr}
\hline Symbol & Description & Running ES \\
\hline KRTAP9-4 & Keratin associated protein 9-4 & 0.542 \\
NME1 & NME/NM23 nucleoside diphosphate kinase 1 & 0.527 \\
KRT80 & Keratin 80, type II & 0.514 \\
KRTAP1-4 & PREDICTED: Homo sapiens similar to keratin associated protein 1.6 (LOC730743), mRNA. & 0.508 \\
NEFH & Neurofilament, heavy polypeptide & 0.491 \\
KRT7 & Keratin 7, type II & 0.464 \\
INA & Internexin neuronal intermediate filament protein, alpha & 0.446 \\
CSNK1A1 & Casein kinase 1, alpha 1 & 0.437 \\
KRT14 & Keratin 14, type I & 0.408 \\
SLC1A4 & Solute carrier family 1 (glutamate/neutral amino acid transporter), member 4 \\
KRTAP4-8 & PREDICTED: Homo sapiens keratin associated protein 4-8, transcript variant 2 (KRTAP4-8), mRNA. \\
KRT86 & Keratin 86, type II & 0.374 \\
KRT17 & Keratin 17, type I & 0.345 \\
NARF & Nuclear prelamin A recognition factor & 0.316 \\
KRTAP2-1 & Keratin associated protein 2-1 & 0.287 \\
KRT81 & Keratin 81, type II & 0.248 \\
KRTAP4-12 & Keratin associated protein 4-12 & 0.215 \\
KRT8 & Keratin 8, type II & 0.167 \\
\hline
\end{tabular}

HDF, human dermal fibroblast; DMSO, dimethyl sulfoxide; ES, enrichment score. 
Supplementary Table 16. Enriched genes of KEGG_PROSTATE_CANCER in DMSO-treated HDFs (aspirin vs. DMSO)

\begin{tabular}{llr}
\hline Symbol & Description & Running \\
\hline$M A P 2 K 1$ & Mitogen-activated protein kinase kinase 1 & -0.418 \\
$R B 1$ & Retinoblastoma 1 & -0.410 \\
$C D K 2$ & Cyclin-dependent kinase 2 & -0.406 \\
PDGFD & Platelet derived growth factor D & -0.394 \\
$M D M 2$ & MDM2 proto-oncogene, E3 ubiquitin protein ligase & -0.381 \\
$T P 53$ & Tumor protein p53 & -0.361 \\
PDGFC & Platelet derived growth factor C & -0.349 \\
$C R E B 5$ & cAMP responsive element binding protein 5 & -0.326 \\
NFKBIA & Nuclear factor of kappa light polypeptide gene enhancer in B-cells inhibitor, alpha & -0.306 \\
$T C F 7 L 2$ & Transcription factor 7-like 2 (T-cell specific, HMG-box) & -0.282 \\
$C C N E 2$ & Cyclin E2 & -0.261 \\
$F G F R 1$ & Fibroblast growth factor receptor 1 & -0.225 \\
$P I K 3 C B$ & Phosphatidylinositol-4,5-bisphosphate 3-kinase, catalytic subunit beta & -0.181 \\
$E P 300$ & E1A binding protein p300 & -0.134 \\
$C T N N B 1$ & Catenin (cadherin-associated protein), beta 1, 88kDa & 0.000 \\
\hline
\end{tabular}

DMSO, dimethyl sulfoxide; HDF, human dermal fibroblast; ES, enrichment score. 
Supplementary Table 17. Enriched genes of KEGG_ARRHYTHMOGENIC_RIGHT_VENTRICULAR_CARDIOMYOPATHY_ARVC in DMSO-treated HDFs (aspirin vs. DMSO)

\begin{tabular}{llr}
\hline Symbol & Description & Running ES \\
\hline$I T G A 1$ & Integrin, alpha 1 & -0.415 \\
$D S C 2$ & Desmocollin 2 & -0.400 \\
$A C T G 1$ & Actin gamma 1 & -0.389 \\
LEF1 & Lymphoid enhancer-binding factor 1 & -0.376 \\
$C A C N B 1$ & Calcium channel, voltage-dependent, beta 1 subunit & -0.367 \\
$I T G A 10$ & Integrin, alpha 10 & -0.363 \\
$I T G A V$ & Integrin, alpha V & -0.349 \\
$S L C 8 A 1$ & Solute carrier family 8 (sodium/calcium exchanger), member 1 & -0.346 \\
$I T G B 3$ & Integrin, beta 3 (platelet glycoprotein IIIa, antigen CD61) & -0.322 \\
$T C F 7 L 2$ & Transcription factor 7-like 2 (T-cell specific, HMG-box) & -0.282 \\
$I T G A 9$ & Integrin, alpha 9 & -0.243 \\
$I T G A 4$ & Integrin, alpha 4 (antigen CD49D, alpha 4 subunit of VLA-4 receptor) & -0.197 \\
$C T N N B 1$ & Catenin (cadherin-associated protein), beta 1, 88kDa & 0.000 \\
\hline
\end{tabular}

DMSO, dimethyl sulfoxide; HDF, human dermal fibroblast; ES, enrichment score. 
Supplementary Table 18. Enriched genes of GO_GENITALIA_DEVELOPMENT in DMSO-treated HDFs (aspirin vs. DMSO)

\begin{tabular}{llr}
\hline Symbol & Description & Running ES \\
\hline WNT5A & Wingless-type MMTV integration site family, member 5A & -0.633 \\
BAK1 & BCL2-antagonist/killer 1 & -0.611 \\
BAX & BCL2-associated X protein & -0.568 \\
$D N A J C 19$ & DnaJ (Hsp40) homolog, subfamily C, member 19 & -0.508 \\
LGR4 & Leucine-rich repeat containing G protein-coupled receptor 4 & -0.449 \\
$T B X 3$ & T-box 3 & -0.364 \\
CTNNB1 & Catenin (cadherin-associated protein), beta 1, 88kDa & 0.000 \\
\hline
\end{tabular}

DMSO, dimethyl sulfoxide; HDF, human dermal fibroblast; ES, enrichment score. 
Supplementary Table 19. Enriched genes of

GO_NEGATIVE_REGULATION_OF_PROTEIN_LOCALIZATION_TO_PLASMA_MEMBRANE in DMSO-treated HDFs (aspirin vs. DMSO)

\begin{tabular}{llr}
\hline Symbol & Description & Running ES \\
\hline NUMB & Numb homolog (Drosophila) & -0.646 \\
CLTC & Clathrin, heavy chain (Hc) & -0.635 \\
TMEM59 & Transmembrane protein 59 & -0.630 \\
LYPLA1 & Lysophospholipase I & -0.590 \\
PID1 & Phosphotyrosine interaction domain containing 1 & -0.532 \\
LZTFL1 & Leucine zipper transcription factor-like 1 & -0.484 \\
GOPC & Golgi-associated PDZ and coiled-coil motif containing & -0.417 \\
GBP1 & Guanylate binding protein 1, interferon-inducible & -0.336 \\
RHOQ & ras homolog family member Q & -0.201 \\
TMBIM1 & Transmembrane BAX inhibitor motif containing 1 & 0.002 \\
\hline DMSO, dim
\end{tabular}

DMSO, dimethyl sulfoxide; HDF, human dermal fibroblast; ES, enrichment score. 
Supplementary Table 20. Enriched genes GO_ENDOTHELIAL_CELL_DEVELOPMENT in DMSO-treated HDFs (aspirin vs. DMSO)

\begin{tabular}{llr}
\hline Symbol & Description & Running ES \\
\hline$A C V R 1$ & Activin A receptor, type I & -0.462 \\
$C L I C 4$ & Chloride intracellular channel 4 & -0.461 \\
$M Y A D M$ & Myeloid-associated differentiation marker & -0.454 \\
STC1 & Stanniocalcin 1 & -0.438 \\
GSTM3 & Glutathione S-transferase mu 3 (brain) & -0.437 \\
RAP2B & RAP2B, member of RAS oncogene family & -0.426 \\
RBPJ & Recombination signal binding protein for immunoglobulin kappa J region & -0.410 \\
$R A B 1 B$ & RAB1B, member RAS oncogene family & -0.387 \\
$F 2 R L 1$ & Coagulation factor II (thrombin) receptor-like 1 & -0.361 \\
RDX & Radixin & -0.335 \\
$S M A D 4$ & SMAD family member 4 & -0.310 \\
$T J P 1$ & Tight junction protein 1 & -0.293 \\
$B M P E R$ & BMP binding endothelial regulator & -0.259 \\
$H E G 1$ & Heart development protein with EGF-like domains 1 & -0.227 \\
$P D E 4 D$ & Phosphodiesterase 4D, cAMP-specific & -0.182 \\
$C T N N B 1$ & Catenin (cadherin-associated protein), beta 1, 88kDa & 0.000 \\
\hline DMSO, dim
\end{tabular}

DMSO, dimethyl sulfoxide; HDF, human dermal fibroblast; ES, enrichment score. 
Supplementary Table 21. Enriched genes of GO_RNA_POLYMERASE_II_ACTIVATING_TRANSCRIPTION_FACTOR_BINDING in DMSO-treated HDFs (aspirin vs. DMSO)

\begin{tabular}{llr}
\hline Symbol & Description & Running ES \\
\hline$N F E 2 L 2$ & Nuclear factor, erythroid 2-like 2 & -0.567 \\
$A T F 2$ & Activating transcription factor 2 & -0.548 \\
$S I N 3 A$ & SIN3 transcription regulator family member A & -0.515 \\
$R B 1$ & Retinoblastoma 1 & -0.489 \\
$B H L H E 40$ & Basic helix-loop-helix family, member e40 & -0.458 \\
$T B X 3$ & T-box 3 & -0.408 \\
$E P 300$ & E1A binding protein p300 & -0.311 \\
$C T N N B 1$ & Catenin (cadherin-associated protein), beta 1, 88kDa & 0.000 \\
\hline
\end{tabular}

DMSO, dimethyl sulfoxide; HDF, human dermal fibroblast; ES, enrichment score. 
Supplementary Table 22. Enriched genes of GO_SMAD_BINDING in DMSO-treated HDFs (aspirin vs. DMSO)

\begin{tabular}{llr}
\hline Symbol & Description & $\begin{array}{l}\text { Running } \\
\text { ES }\end{array}$ \\
\hline$T G I F 1$ & TGFB-induced factor homeobox 1 & -0.487 \\
$M A G I 2$ & Membrane associated guanylate kinase, WW and PDZ domain containing 2 & -0.481 \\
$T G F B R 3$ & Transforming growth factor, beta receptor III & -0.469 \\
$P P M 1 A$ & Protein phosphatase, Mg2+/Mn2+ dependent, 1A & -0.456 \\
USP9Y & Ubiquitin specific peptidase 9, Y-linked & -0.454 \\
SMAD4 & SMAD family member 4 & -0.437 \\
BMPR1A & Bone morphogenetic protein receptor, type IA & -0.427 \\
AXIN2 & Axin 2 & -0.417 \\
$T O B 1$ & Transducer of ERBB2, 1 & -0.383 \\
ZEB2 & Zinc finger E-box binding homeobox 2 & -0.348 \\
$E P 300$ & E1A binding protein p300 & -0.308 \\
EID2 & EP300 interacting inhibitor of differentiation 2 & -0.257 \\
$F L N A$ & Filamin A, alpha & -0.200 \\
$M E F 2 A$ & Myocyte enhancer factor 2A & -0.139 \\
$C T N N B 1$ & Catenin (cadherin-associated protein), beta 1, 88kDa & 0.000 \\
\hline
\end{tabular}

DMSO, dimethyl sulfoxide; HDF, human dermal fibroblast; ES, enrichment score. 